\title{
Clinical pharmacology of fluconazole in infants and children
}

\author{
Gian Maria Pacifici* \\ Associate Professor of Pharmacology, via Sant'Andrea 32, 56127 Pisa, Italy
}

\begin{abstract}
Fluconazole is the most potent antifungal agent, after metabolic conversion to 5-fluorouracil, by the enzyme uracil phosphoribosyl transferase, is either incorporated into RNA or metabolized to 5-fluoro-2'-deoxyuridine-5'monophosphate, a potent inhibitor of thymidylate synthase, ultimately inhibition of DNA synthesis. Fluconazole is active against several Candida species, Blastomyces dermatitis, Human capsulatum, and Coccidioides species, Paracoccidioides brasiliensis, and ringworm fungi (dermatophytes). Fluconazole is also active against Aspergillus species, Scedosporium apiospermun (Pseudallescheria boydii), Fusarium, and Sporothrix schenckii, but these fungi are intermediate in susceptibility. Fluconazole penetration into cerebrospinal fluid is good and it successfully treated bacterial meningitis. Fluconazole is used either for prophylaxis and treatment of fungal infection and colonization either in infants and children. In infants, fluconazole treatment dosing-regimen consists of a loading dose $(25 \mathrm{mg} / \mathrm{kg}$ ) followed by a daily maintenance dose of $12 \mathrm{mg} / \mathrm{kg}$, whose dosing intervals decrease according to postnatal age. In children, the recommended dose is of $12 \mathrm{mg} / \mathrm{kg}$ daily without loading dose. Following oral dosing, this antibiotic is well absorbed, mainly by small intestine, its bioavailability is about $100 \%$, and it is almost completely eliminated by kidney. Half-life is lower in preterm and term infants ( 40 to 60 hours) compared to children (< 20 hours) because renal function is lower in infants, and it increases with infant maturation. Fluconazole has been found to be effective and safe in infants and children, however, it produces several birth-defects when administered at high doses, (400 mg daily) to pregnant women. This drug is metabolically cleared by CYP3A enzymes, and interacts with different drugs which are metabolized by CYP3A, enhancing or inhibiting their effects, pharmacokinetics or metabolism. Several Candida species may become resistant to fluconazole; the resistance-rate is flung-specie depended, and azole consumption causes fluconazole-resistance rate increasing infection-risks. The aim of this study is to review published data on fluconazole dosing, effects, distribution, prophylaxis, treatment, drug-interactions, meningitis, trials, metabolism, pharmacokinetics, and drug-resistance in infants and children.
\end{abstract}

\section{Introduction}

Fluconazole is commonly used both to prevent and to treat invasive Candida albicans. This antibiotic is a potent, selective, triazole-inhibitor of the fungal enzymes involved in ergosterol synthesis. Fluconazole is reasonably effective against most Candida species, other than Candida glabrata. It is also of value in treatment of Cryptococcal infection. It is water soluble, well absorbed by mouth even in infancy, and largely excreted unchanged in the urine. Penetration into the cerebrospinal fluid is good. Fluconazole is increasingly used in treatment of systemically invasive Candida albicans infection. Studies suggest that it is less toxic, and at least as effective as amphotericin B. Liver function eruptions have only been seen in immunodeficient patients. Over $90 \%$ of an oral fluconazole dose is absorbed. It is widely distributed through the body, and then it is excreted by the kidney, in about $80 \%$ as unchanged compound and $11 \%$ as metabolites. The half-life in preterm infants with 29 weeks postmenstrual age is just over 70 hours. In term infants it is 40 to 60 hours, but changes within the first two weeks before setting at 20 to 25 hours throughout infancy and childhood, setting to 30 hours in adults. There is no good reason to give amphotericin B as well has high-dose fluconazole, but there is evidence that effective treatment of all Candida species, with MIC of $\leq 8 \mu \mathrm{g} / \mathrm{ml}$, requires a higher-dose than much reference text currently quote. In-vitro modelling also suggests that high-dose treatment makes the emergence of resistant strains less likely. Oral fluconazole is widely used to treat superficial, thus topic, infection in adults and is now starting to be used for this purpose in infants. Prophylactic use has been widely studied in the last ten years, but some prefer to use nystatin which is not systemically absorbed, to minimize the risk of fluconazole-resistant strains proliferating. There is also some debate whether universal prophylaxis is warranted in units where of invasive candidiasis are low, whilst there is good evidence that this strategy is useful in those units that have moderate-to-high rates of invasive candidiasis, the evidence is less compelling when rates are low. While high-dose systemic exposure, such as $400 \mathrm{mg}$ daily in the first trimester of pregnancy can produce a constellation of serious foetal abnormalities there are, as yet, no reports of teratogenicity with a single $150 \mathrm{mg}$ daily-dose in the first trimester, or with topical or oral use later in pregnancy For Candida infection of the breast, the mother should take 100 to $300 \mathrm{mg}$ loading dose and then 100 to $200 \mathrm{mg}$ daily for at least ten days. Treat the infant as well and take steps to minimize the risk of re-infection [1].

All susceptible fungi are capable of deaminating flucytosine to 5-fluorouracil a potent antimetabolite that is used in cancer chemotherapy. Fluorouracil is metabolized first to 5-fluorouracilribose monophosphate by the enzyme uracil phosphoribosyl transferase. 5- Fluorouracil-ribose monophosphate is then either incorporated into RNA (via synthesis of 5-fluorourine triphosphate)

${ }^{\star}$ Correspondence to: Gian Maria Pacifici, Associate Professor of Pharmacology, via Sant'Andrea 32, 56127 Pisa, Italy; E-mail: pacifici44@tiscali.it

Key words: fluconazole, dosing, effects, distribution, prophylaxis, treatment, druginteraction, cerebrospinal fluid, meningitis, trials, metabolism, pharmacokinetics, resistance, infants, children

Received: August 01, 2020; Accepted: August 11, 2020; Published: August 18 2020 
or metabolized to 5-fluoro-2'-deoxyuridine-5'-monophosphate, a potent inhibitor of thymidylate synthase, ultimately inhibiting DNA synthesis. The selective action of flucytosine is due to the lack of cytosine deaminase in mammalian cells, which prevents metabolism to fluorouracil. Fluconazole is active against several Candida species, Blastomyces dermatitis, Human capsulatum, and Coccidioides species, Paracoccidioides brasiliensis, and ringworm fungi (dermatophytes). Fluconazole is also active against Aspergillus species, Scedosporium apiospermun (Pseudallescheria boydii), Fusarium, and Sporothrix schenckii, but these fungi are intermediate in susceptibility. Candida glabrata exhibits reduced susceptibility to azoles, whereas Candida krusei and the agents of mucormycosis are resistant. Posaconazole and isavuconazole have modestly improved spectrum of activity in-vitro against the agents of mucormycosis. Fluconazole is the drug of choice for treatment of Coccidioidal meningitis because of good penetration into cerebrospinal fluid and much less morbidity than the intrathecal amphotericin B. Fluconazole is almost completely absorbed from the gastrointestinal-tract and plasma concentration is essentially the same when the drug is administered orally or intravenously, and its bioavailability is unaltered by food or gastric acidity. This antibiotic diffuses readily into body fluids, including breast-milk, sputum and saliva. Concentration in the cerebrospinal fluid can reach 50 to $90 \%$ of the simultaneous values in plasma. Fluconazole is active against all susceptible fungi which are capable of deaminating flucytosine to 5-fluorouracil, a potent antimetabolite that is used in cancer chemotherapy [2].

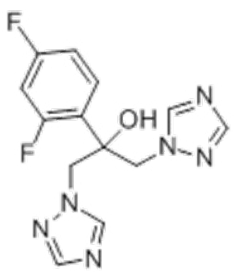
mole)

\section{Literature search}

The literature search was performed electronically using PubMed database as search engine, the cut-off point was April 2020. The following key words: "fluconazole infants effects", "fluconazole children effects", "fluconazole infants metabolism", "fluconazole children metabolism", "fluconazole infants pharmacokinetics", "fluconazole children pharmacokinetics", "fluconazole infants resistance", and "fluconazole children resistance" were used. In addition, the books Neonatal Formulary [1] and The Pharmacological Basis of Therapeutics [2] were consulted. The manuscript is written according to "Instructions for Authors".

\section{Results}

\section{Fluconazole administration dosing schedules of in infants and children}

Fluconazole prophylaxis in very low birth-weight infants. Infants aged $<2$ weeks, give $6 \mathrm{mg} / \mathrm{kg}$ fluconazole on day 1 , then a further 6 $\mathrm{mg} / \mathrm{kg}$ every third day. Infants aged two to four weeks, give $6 \mathrm{mg} / \mathrm{kg}$ fluconazole and day 1 , then a further $6 \mathrm{mg} / \mathrm{kg}$ every second day [1].

Fluconazole treatment of invasive candidiasis in infants. Fluconazole loading dose $(25 \mathrm{mg} / \mathrm{kg})$ shortens the time to achieving therapeutic concentrations. Give $12 \mathrm{mg} / \mathrm{kg}$ fluconazole once-daily, every day, to infants with a postmenstrual age $<30$ weeks. For postmenstrual age $>$ 30 weeks, give $20 \mathrm{mg} / \mathrm{kg}$ fluconazole once-daily, every day. Double the dosage interval after the first two doses if there is renal failure [1].

Fluconazole treatment of children. Give $12 \mathrm{mg} / \mathrm{kg}$ once-daily, maximum $600 \mathrm{mg}$ daily, without a loading dose [2].

\section{Fluconazole absorption following oral administration to children}

Cristofoletti et al. [3] studied the absorption of fluconazole in children. Blood in the small intestine ranges from 5 to $40 \mathrm{~L} / \mathrm{h}$, is represented by an age-depended nonlinear function, reaching asymptote at 15 years. Luminal bile salts concentrations under fasting state are described by non-monotonic age depended functions, graphically represented by an inverted $U$-shape, with an ascending phase from 1 to 10 years with a maximum duodenal concentration of $9 \mathrm{mM}$, then a descending phase from 1 to 10 years, at which age adult values are reached. Gastric $\mathrm{pH}$ in children was described in an age-depended way, being neutral in infants and reaching adult values by 2 years of age. Even though the lower adsorptive surface and smaller volumes of intestinal fluids in children does not affect fluconazole absorption and the absorption-rate constant rate is $1.8 \mathrm{~h}^{-1}$.

Schäfer-Korting [4] described the absorption of azole compounds and observed that the absorption-rate of these drugs is impaired by gastric $\mathrm{pH}$, which is observed in some patients with acquired immunodeficiency syndrome. It is also impaired by frequent vomiting, which commonly occurs in patients with neutropenia. The concomitant administration of cyclosporine reduces fluconazole concentration by 50 to $55 \%$.

Nahata and Brady [5] investigated fluconazole pharmacokinetics in fasting children, aged 5 to 13 years, with HIV-infection. This antibiotic was administered orally at a dose of either 2 or $8 \mathrm{mg} / \mathrm{kg}$. Fluconazole achieved serum concentration in these children similar to that of adults indicating a nearly complete degree of absorption.

Gupta et al. [6] observed that fluconazole has excellent absorption and good persistence in tissues that suggest it may be useful in superficial fungal infection.

\section{Fluconazole efficacy and safety in infants and children}

Castagnola et al. [7] described fluconazole efficacy and safety in infants. Although clinical use has been wide for over 15 years, there have been few studies about its safety and efficacy in young infants. These authors observed that fluconazole was found to be efficacy and safe in infants admitted in a neonatal intensive care unit.

Murata et al. [8] observed that fluconazole is efficacy and safety in infants in children and adverse-drug reactions were observe in only one patient, among 27 patients, who developed liver disorder, thus adverse-effect-rate was 3.7\%. No serious or unanticipated adverse-drug reactions were observed, fluconazole was found to be efficacy and safe, and no remarkable findings should require additional precautions.

Lee et al. [9] observed that in highest-risk group, consisting in extremely low birth-weight infants $(<1,000$ gram $)$, invasive fungal infection increases mortality-rate and neurodevelopment in patients, despite antifungal therapy. With respect to fluconazole, other concerns are short-term drug toxicities and long-term neurodevelopment consequences due to fluconazole treatment when it is used in a developing organism. 
Gürpinar et al. [10] studied fluconazole efficacy and safety in 24 infants, aged 2 days to 10 months, having fungal infection, who were treated with fluconazole by intravenous infusion, at a dose of $6 \mathrm{mg} /$ $\mathrm{kg}$ daily (range, 2 to 16), for a mean treatment duration of 25 days (range, 5 to 72). Fluconazole was found to be effective, positive clinical response was achieved in 23 of 24 infants (95.8\%); eradication of fungal organism was also achieved in 23 of 24 infants (95.8\%). Adverse-effects occurred in only two infants $(8.3 \%)$ but therapy was not discontinued in both infants. These results confirm fluconazole efficacy and safety in the treatment of infants suffering from severe fungal infection.

Fasano et al. [11] prospectively evaluated fluconazole effects in 40 infants, aged 2 days to 3 months, in whom conventional antifungal therapy was ineffective or contraindicated. Fluconazole was administered at a mean dose of $5.3 \mathrm{mg} / \mathrm{kg}$ daily (range, 1 to 16), and mean duration of therapy was 26 days (range, 2 to 80 ). Efficacy was evaluated in 31 of 32 infants (96.9\%) with proven fungal infection, and eradication of fugal organisms was achieved in 30 of 31 infants $(96.8 \%)$. Adverse-effects occurred in only two infants (6.2\%), but therapy was not discontinued in both infants.

Schwarze et al. [12] reviewed optimal fluconazole dosing-regimens in order to establish efficacy and safety. These authors included 726 children, aged $<1$ year, who derived from 78 studies. Fluconazole dose ranged from 2 to $50 \mathrm{mg} / \mathrm{kg}$ daily, and 162 days was maximum treatment duration. Fluconazole was well tolerated and was efficacious against systemic candidosis.

Novella and Holden [13] determined fluconazole safety profile in 562 children, aged 0 to 17 years, most children received multiple oral fluconazole dose (range, 1 to $12 \mathrm{mg} / \mathrm{kg}$ ), and only few received a single dose. The most common adverse-effects were gastrointestinal (7.7\%) or skin (1.2\%). Overall, 18 children (3.2\%) discontinued treatment due to severe adverse-effects. Although $98.6 \%$ of children were taking concomitant medications, no clinical and laboratory interactions were observed. Fluconazole was well tolerated in children mirrors the excellence safety profile.

\section{Fluconazole prophylaxis in preterm infants}

Autmizguine et al. [14] performed a multicentre, randomized, placebo-controlled trial of fluconazole prophylaxis, in order to test susceptibility of Candida isolates to fluconazole. One-hundredeight premature infants ( $<750$ gram birth-weight) were enrolled and received fluconazole, whereas 173 infants received placebo. Cultures were assessed at baseline (study period day 0 to 7 ), period 1 (study day 8 to 28), and period 2 (study period day 29 to 49). Fluconazole MICs were determined for all Candida species. Candida colonization was significantly lower in fluconazole group compared to placebo, during periods 1 (5 versus 27\%, P-level< $<.001$ ) and period 2 (3 versus $27 \%$, $\mathrm{P}$-value $<0.001)$. Only two infants $(1 \%)$ were colonized with at least one fluconazole-resistant Candida. Median fluconazole MIC was similar in both treatment groups at baseline and period 1. However, in period 2, median MIC was higher in the fluconazole group compared to placebo (1.00 versus $0.5 \mu \mathrm{g} / \mathrm{ml}, \mathrm{P}$-value $=0.01)$. There was no emergence of resistance observed, and no infants developed invasive candidiasis with a resistant Candida isolate. Fluconazole prophylaxis decreased Candida albicans and 'non-albicans' colonization, thus its use is appropriate in infants.

Ericson et al. [15] identified all randomized, placebo-controlled trials evaluating fluconazole prophylaxis in preterm infants conducted in the US. The occurrence of each endpoint in infants who received prophylaxis with fluconazole versus placebo was compared. Endpoints evaluated were: invasive candidiasis, death, Candida colonization, and fluconazole-resistance among tested isolates. Infants receiving fluconazole prophylaxis had reduced odds of invasive candidiasis, death, and Candida colonization compared to infants giving placebo. Thus, fluconazole prophylaxis is effective and safe in reducing invasive candidiasis, and had no impact on resistance was observed.

Kaufman et al. [16] conducted a prospective, randomized, doubleblind clinical trial over a 30 month period in 100 preterm infants with birth-weight $<1,000$ gram, to assess prophylaxis efficacy. Infants were randomly assigned to receive either fluconazole $(\mathrm{N}=50)$ or placebo $(\mathrm{N}=50)$ for 6 weeks. Fungal colonization was documented in 30 infants, in the placebo group (60.0\%), and in 11 infants in the fluconazole group $(22.0 \%, P$-value $=0.02)$. Fungal infection was observed in blood, urine, or cerebrospinal fluid of 10 infants $(22.0 \%)$ who received placebo, and none infant treated with fluconazole $(\mathrm{P}$-value $=0.008)$. Fluconazole prophylaxis prevented fungal colonization and invasive fungal infection in these infants.

Weitkamp et al. [17] assessed prophylaxis efficacy in preterm infants, 44 infants received prophylaxis, whereas 42 infants did not. In prophylaxis group, no invasive fungal infection was observed, whereas it compared in nine infants of no-prophylaxis group $(\mathrm{P}=0.004)$. No significant adverse effects were recorded, fluconazole prophylaxis was found to be effective and safe in preventing invasive fungal infections.

Aziz et al. [18] undertook a retrospective study to document the efficacy and adverse-effects or routine fluconazole prophylaxis. Extremely-low-birth-weight infants were divided into two groups: control group $(\mathrm{N}=99)$ and fluconazole group $(\mathrm{N}=163)$. Invasive fungal infection occurred in $7.1 \%$ in the control group versus $1.8 \%$ in the fluconazole group ( $\mathrm{P}$-value $=0.045)$. Logistic regression analysis revealed that fluconazole prophylaxis was associated with a lower-risk of invasive fungal infection.

\section{Fluconazole treatment in infants and children}

Gürpinar et al. [19] described fluconazole treatment in 24 infants, aged 2 days to 10 months, with documented fungal infection. Fluconazole was administered at a mean dose of $6 \mathrm{mg} / \mathrm{kg}$ (range, 2 to 16) daily and mean treatment duration was 25 days (range, 5 to 72 ). A positive clinical response was achieved in 23 of 24 infants (95.8\%), and adverse-effects were observed in only two infants (8.3\%). These results confirm fluconazole efficacy and safety in treatment in infants with severe fungal infections.

Charlier et al. [20] observed that Candida species are responsible for most of mucosal and invasive candidiasis. These authors reviewed the main available data on the position of fluconazole in prophylaxis or curative treatment of invasive infections caused by Candida specie infections. Case repots and uncontrolled studies documented fluconazole efficacy in curing osteoarthritis, endocarditis, meningitis, endocarditis, and peritonitis caused by Candida species in adults. Fluconazole is still the first-line treatment option for several cases of invasive candidiasis; however, its prophylactic use should be limited to selected high-risk patients to limit emergence-risk of strains azoleresistant.

Kakourou and Uksal [21] described practice guidelines for treatment of Tinea capitis; topical treatment is only used as adjuvant therapy to systemic antifungals. Fluconazole was found to be efficacy and had potential adverse-effects similar to that of griseofulvin in children with Tina capitis infection caused by Trichophyton species. 
Fluconazole may be more expensive and griseofulvin is still the treatment of choice for infections caused by Microsporum species, however, griseofulvin is nowadays not available in certain European countries.

Iosifidis et al. [22] reviewed the main indications for antifungal drug administration in paediatrics, and stated that fluconazole remains the most frequent antifungal prophylactic agent given to high-risk infants and children. However, the emergence of fluconazole-resistance, particularly in non-albicans Candida species, should be considered during preventive or empiric therapy.

Ben-Ami [23] observed that invasive candidiasis occurs frequently in hospitalized patients, and is associated with high mortality-rate. Fluconazole is the drug of choice in management of invasive candidiasis, however, one must take into account multiple hosts, pathogens, and drug-related factors, including the site of infection, host immune status, severity of sepsis, resistance, tolerance, biofilm formation, and pharmacokinetics/pharmacodynamics to this antifungal agent.

Michelerio et al. [24] retrospectively studied three cases of cutaneous lesishmaniasis in paediatric patients, aged 3 to 6 years, treated with fluconazole. Efficacy, tolerability, safety profile and the cosmetic results of fluconazole were examined after administration of a dose of $6 \mathrm{mg} / \mathrm{kg}$ for 6 weeks. Children had complete resolution of their lesions with minimal scarring, and no adverse-effects were reported. Fluconazole represents a valid, safe and easily manageable option for lesishmaniasis in paediatric patients.

Watt et al. [25] determined fluconazole dosing in children on extracorporeal membrane oxygenation, and developed a physiologically based pharmacokinetic model in adults and critically ill children. Simulations, using the final extracorporeal membrane oxygenation and based pharmacokinetic model, reasonably characterized observed pharmacokinetic data in children with extracorporeal membrane oxygenation support, and the model was used to derive dosing across the paediatric age spectrum, in patients on extracorporeal membrane oxygenation.

Sesmero et al. [26] assessed fungal chemoprophylaxis safety in 60 infants, weighing $<1,500$ gram, and with postmenstrual age $<28$ weeks. Fluconazole was intravenously infused and a pharmacotherapeutic follow-up was performed for one year. No significant drug interactions and adverse-effects were observed. Fluconazole chemoprophylaxis was found to be excellent regarding to effectiveness, safety and tolerability.

Fox et al. [27] evaluated the physical compatibility of various drugs, including fluconazole, with neonatal total parenteral nutrition solution during simulated Y-site administration. Injection of equal volumes of neonatal total parenteral nutrition solution or sterile water was combined with the drugs or sterile water. Samples were examined via turbidmetric analysis and visually against light and dark backgrounds immediately, and after five times from administration ranging from 0.25 to 3 hours. Phenobarbital, pentobarbital, and rifampin formed visible precipitation immediately after mixing with the neonatal total parenteral nutrition solution. Fluconazole exhibited no visual or turbidmetric evidence of incompatibility when combined with a neonatal total parenteral nutrition solution for up to three hours in a simulated Y-site injection, thus fluconazole may be co-administered with total parenteral nutrition solution.

Nwaroh et al. [28] stated that sirolimus, an immunosuppressant drug, is indicated for post-allogenic stem cell transplant to reduce the risk of graft-versus-host disease. Sirolimus is metabolized by CYP3A4 and is a substrate of P-glycoprotein drug efflux-pump. Fluconazole may interact with known inhibitors of CYP3A4 enzyme and P-glycoprotein. Co-administration of fluconazole resulted in a decline in sirolimus blood concentrations, leaving patients at risk of graft-versus-host disease. In three patients studied, fluconazole discontinuation resulted in marked reduction in sirolimus trough concentrations, requiring $>$ $200 \%$ increase in sirolimus dose to achieve therapeutic concentrations. Fluconazole should be not co-administered with sirolimus.

Liu and Köhler [29] observed that ill patients, at risk of invasive candidiasis, often receive multiple medications, including protonpump inhibitors. Fluconazole perturbs the vacuolar proton ATPase, and the proton-pump inhibitor omeprazole which inhibits Candida albicans growth. A Candida albicans codon-adapted pHluorin, Candida albicans pHluorin, was generated to assess cytosolic $\mathrm{PH}$. Fungal cytosol was acidified by omeprazole and re-alkalinized by coexposure to fluconazole. Off-target effects of any medication on fungal pathogens may occur.

\section{Fluconazole drug-interactions}

Fluconazole interacts with many drugs; it enhances or inhibits drug effects, metabolism or pharmacokinetics. Levin et al. [30] reported two cases of life-threatening serotonin toxicity due a drug interaction between citalopram and fluconazole. Fluconazole inhibits CYP2C19 and citalopram is a substrate of CYP2C19, co-administration of fluconazole and citalopram results in alteration of citalopram with consequent serotonin toxicity.

Black et al. [31] observed that fluconazole, administered at a dose of $400 \mathrm{mg} / \mathrm{kg}$ for 6 days to 6 volunteers, significantly reduced warfarin metabolic clearance, as this drug is metabolized by CYP enzymes. In particular, CYP2C9 catalyses 6- and 7-hydroxylation of (S)-warfarin, responsible of warfarin termination anticoagulant effect, and coadministration of fluconazole inhibited approximately $70 \%$ of warfarin metabolism. This interaction dramatically increased the magnitude and duration of warfarin's hypoprothrombinaemic effect. (R)-Warfarin clearance was also strongly inhibited by fluconazole. 10-Hydroxilation, a metabolic pathway catalysed exclusively by CYP3A4, was inhibited by $45 \%$, whereas 6-, 7-, and 8-hydroxylations were inhibited by 61,73 , and $88 \%$, respectively. Fluconazole interacts with any drugs whose metabolic clearance is dominated by CYP2C9 and CYP3A4, and strongly support the hypothesis that effects based, in-vivo drug interactions, may be predicted from in-vitro microsomal data.

Yang et al. [32] examined the allosteric effect of fluconazole (effector) on the formation of 1'-hydromidazolam and 4-hydroxymidazolam from midazolam, which is a substrate for CYP3A4 and CYP3A5 in humans. Following fluconazole pre-treatment, 4-OH-midazolam and midazolam AUC values increased by 35 to $62 \%$, respectively, whereas, AUC 1'-hydromidazolam to midazolam ratio decreased by 5 to $37 \%$, and AUC 1'-hydromidazolam to 4-OH-midazolam ratio decreased by 46 to $58 \%$. Fluconazole decreased the intrinsic formation-clearance of 1'-hydromidazolam and 4-OH-midazolam. Fluconazole alters formation-rate of midazolam metabolites, in a manner consistent with allosteric interaction.

Finch et al. [33] described elevated carbamazepine serum concentrations during concomitant fluconazole (400 $\mathrm{mg} / \mathrm{kg}$ daily) administration, including serial concentrations both before and after therapy with this antifungal agent. Inhibition of carbamazepine metabolism is altered by fluconazole, a known inhibitor of cytochrome P450 enzyme system. 
Hilber et al. [34] evaluated the pharmacokinetic interaction between fluconazole $150 \mathrm{mg}$ twice-daily, administered for one week, and oral ethinyl estradiol and norethindrone in 26 healthy women aged 18 to 36 years. Treatment with fluconazole resulted in significant increase of $\mathrm{AUC}_{0-24 \text { hours }}$ for both ethinyl estradiol (24\%) and norethindrone $(13 \%)$ as compared to placebo. The concomitant administration of $300 \mathrm{mg}$ fluconazole, twice the recommended dose for vaginal candidiasis, resulted in significant increase of blood concentration of ethinyl estradiol and norethindrone.

Blum et al. [35] performed a randomized, placebo-controlled, parallel study, to assess fluconazole effect on phenytoin. Twenty healthy male subjects received $200 \mathrm{mg}$ daily phenytoin orally on days 1 to 3 and 18 to 20 , and $250 \mathrm{mg}$ intravenously on days 4 and 21 . Fluconazole trough concentration was determined on days 14,18 , and 21. Phenytoin AUC $_{0-24 \text { hours }}$ increased $75 \%$ and trough plasma concentration increased up to $128 \%$ after fluconazole administration. Fluconazole inhibits phenytoin metabolism with a consequent alteration of phenytoin serum concentration. Serum levels of this drug should be monitored, and phenytoin dosage is clinically warranted in patients receiving fluconazole.

Cobb et al. [36] determined fluconazole effect on methadone disposition in health volunteers who received methadone orally at a dose of $200 \mathrm{mg}$ daily and fluconazole $(\mathrm{N}=13)$ or placebo $(\mathrm{N}=12)$ for 14 days. There was a $35 \%$ increase of both methadone serum concentration and AUC in patients treated with fluconazole (P-value $=0.0008$, for both parameters). Methadone peak and trough concentrations increased by $27 \%$ ( $\mathrm{P}$-value $=0.0076$ ) and $48 \%$ (P-value $=0.0007$ ), respectively, compared to those obtained in subjects who received placebo. Fluconazole alters methadone peak and though concentrations.

Kang et al. [37] assessed fluconazole effect on omeprazole pharmacokinetics in 18 healthy volunteers. Control subjects received omeprazole dose of $20 \mathrm{mg}$ daily, and treated subjects received omeprazole plus $100 \mathrm{mg}$ fluconazole daily for 4 days. Omeprazole is extensively metabolized through 5-hydroxylation and sulfoxidation catalysed by $\mathrm{CYP} 2 \mathrm{C} 19$ and $\mathrm{CYP} 3 \mathrm{~A} 4$, respectively. Fluconazole is a potent competitive inhibitor of $\mathrm{CYP} 2 \mathrm{C} 19$, and a weak inhibitor of CYP3A4. In treated subjects, omeprazole $\mathrm{AUC}_{0-\infty}$ elimination half-life, and peak plasma concentration were significantly greater (3,0 versus $0.5 \mu \mathrm{g} . \mathrm{h} / \mathrm{ml}),(2.59$ versus 0.85 hours $)$, and $(0.75$ versus $0.31 \mu \mathrm{g} / \mathrm{ml})$, respectively, compared to control subjects. Fluconazole is a potent inhibitor of omeprazole metabolism.

\section{Fluconazole penetration into cerebrospinal fluid of infants and children}

Gerhart et al. [38] characterized fluconazole exposure in plasma of 22 infants with mean postmenstrual age of 28 weeks (range, 24 to 50), and in cerebrospinal fluid of 27 infants with a mean postmenstrual age of 28 weeks (range, 24 to 33). Cerebrospinal fluid concentration ranged from 0.1 to $9.6 \mu \mathrm{g} / \mathrm{ml}$ and was obtained 3.3 to 219 hours from the last dose. Drug penetration into the brain was determined by the following equation:

$$
\mathrm{P}=\frac{\left.\mathrm{MW}_{\text {eff }}{ }^{\star} 10^{9}\right)^{-6} *}{(366)^{-6}} \frac{10^{\log \mathrm{P}} \cdot 10^{-5}}{5}
$$

Where: $\mathrm{P}$ is the specific organ permeability, $\mathrm{MW}_{\text {eff }}$ is the effective molecular weight, and $\log \mathrm{P}$ is the lipophilicity.

Cerebrospinal fluid and plasma samples were obtained 1,470 and $1,474 \mathrm{~min}$, respectively, after the last dose of $25 \mathrm{mg} / \mathrm{kg}$. Cerebrospinal fluid to plasma ratio was 0.98 , suggesting that fluconazole penetrates blood brain barrier easily, and fluconazole target attainment was reached in plasma and cerebrospinal fluid.

Bafeltowska and Buszman [39] examined fluconazole pharmacokinetics in cerebrospinal fluid of two children with hydrocephalus. Fluconazole was intravenously infused at average multiple doses of $12.5 \mathrm{mg} / \mathrm{kg}$ daily, and was injected into the cerebrospinal fluid at doses of 4,5 , and $7.5 \mathrm{mg} / \mathrm{kg}$ once-daily, and 7.5 to $10 \mathrm{mg} / \mathrm{kg}$ twicedaily. Fluconazole cerebrospinal fluid concentration was undetectable after intravenous administration. Fluconazole pharmacokinetics were determined in cerebrospinal fluid after intraventricular administration, and steady-state peak and trough concentrations were: $19.5+4.63$ and 0.0 to $0.3 \mu \mathrm{g} / \mathrm{ml}$, respectively. Elimination rate constant and half-life were: $0.465+0.210 \mathrm{~h}^{-1}$ and $1.84+0.93$ hours, respectively. These results suggest the necessity of fluconazole monitoring in children with hydrocephalus during treatment of shunt infection.

\section{Fluconazole treatment of meningitis in infants and children}

Huttova et al. [40] studied fluconazole treatment of meningitis in 40 infants, of whom 28 were very-low-birth-weight infants, and all infants had documented Candida albicans or Candida parapsilosis fungemia. Fluconazole was intravenously infused at a dose of $6 \mathrm{mg} / \mathrm{kg}$ once-daily for 6 to 48 days, 34 infants received fluconazole as a monotherapy and 6 infants were treated with a combination of fluconazole and amphotericin B. Thirty-two infants $(80.0 \%)$ were cured; 4 of them relapsed at least after 14 days of therapy, but they were ultimately cured without sequelae. Two infants had elevated liver enzymes and 2 other had elevated serum creatinine concentration during fluconazole monotherapy. No therapy discontinuation was necessary in one infant. Fungal meningitis developed as a complication of fungemia in 8 infants. Fluconazole successfully treated meningitis caused by Candida albicans or Candida parapsilosis even in complicated Candida fungemia.

Pérez et al. [41] observed that meningitis follows approximately $0.1 \%$ to $0.75 \%$ of cases of extra-pulmonary coccidioidomycosis. Fluconazole has a good cerebrospinal fluid penetration and a favourable side-effect profile. Eleven children, suffering from coccidioidal meningitis, were treated with amphotericin $B$, and they were switched to oral fluconazole at a dose of $400 \mathrm{mg}$ daily for up to 19 months. Three children required hospitalization, two of them for reasons unrelated to coccidioidal meningitis. No child developed extra-meningeal disease or required discontinuous of fluconazole therapy. Conversion from amphotericin $\mathrm{B}$ to fluconazole was associated with stable disease course of coccidioidal meningitis for up to 19 months.

\section{Fluconazole migration into breast-milk}

Little is known about fluconazole migration into breast-milk. Kaplan and Koren [42] obtained breast-milk samples 8 days after delivery, at the $18^{\text {th }}$ day of treatment. Fluconazole maximum concentration in breast-milk was $4.1 \mu \mathrm{g} / \mathrm{ml}$, measured 2 hours after the dose. The estimated relative infant dose was $17 \%$, and elimination half-life in breast-milk was 26.9 hours. In another report, fluconazole breast-milk concentration was $2.93,2.66,1.76$, and $0.98 \mu \mathrm{g} / \mathrm{ml}$, at 2 , 5,24 , and 48 hours, respectively, after an oral dose of $150 \mathrm{mg}$. The estimated relative infant dose was $17 \%$, and elimination half-life was 30 hours in breast-milk. Both studies are consistent with the view than fluconazole half-life is longer in breast-milk than in serum of healthy volunteers. 


\section{Fluconazole administered during pregnancy causes birth- defects}

Liu et al. [43] reviewed 8 cohort studies and one case-control study. Oral fluconazole exposure during pregnancy increased the risk of congenital heart defects and itraconazole caused eye defects in foetuses.

Mølgaard-Nielsen et al. [44] studied the association between oral fluconazole exposure during pregnancy and the risk of spontaneous abortion and stillbirth. Among 3,315 women exposed to oral fluconazole, from 7 through 22 weeks of gestation, 147 (4.4\%) experienced a spontaneous abortion. Among 5,382 women exposed to fluconazole, from week 7 to delivery, 21 experienced a stillbirth occurring at $0.4 \%$, compared to 77 among 21,506 unexposed (0.3\%). Using topical azole exposure as the comparison, 137 of 2,823 women (4.8\%) exposed to systemic fluconazole versus 118 of 2,823 (4.2\%) exposed to topical azoles had a spontaneous abortion; 20 of 4,301 (0.4\%) exposed to systemic fluconazole versus 22 of 4,301 (0.5\%) exposed to topical azoles had a stillbirth. Use of oral fluconazole in pregnancy was associated with a statistically significant increased-risk of spontaneous abortion compared to risk among unexposed women, and women with topical azole exposure in pregnancy.

Howley et al. [45] observed that of 43,257 mothers analysed, 44 pregnant women, who received fluconazole, and only 6 control mothers' generated infants with birth-defects. Six exposed infants had cleft lip with cleft palate, 4 had an atrial septal defect, and each of the following defects had 3 exposed cases: hypospadias, tetralogy of Fallout, d-transposition of the great arteries, and pulmonary valve stenosis. Fluconazole use was associated with cleft lip, cleft palate (odds ratio $=5.53$, confidence interval $=1.68-18.24)$ and $d$-transposition of the great arteries (odds ratio $=7.56$; confidence interval $=1.22-35.45$ ). The associations between fluconazole and both cleft lip with cleft palate and d-transposition of the great arteries are consistent with earlier published case reports but not recent epidemiologic studies. These reported birthdefects are consistent with earlier published cases.

Pursley et al. [46] enrolled three infants born to women who received fluconazole through or beyond the first trimester of pregnancy. All infants had congenital anomalies; no other drugs were implicated, and only one of three infants survived. Their anomalies, similar to those observed in animal studies, were largely craniofacial, skeletal (i.e., thin, wavy ribs and ossification defects), and cardiac. One of these infants was previously reported as having Antley-Bixler syndrome; however, given the chronology described herein and the similarity of this infant to the others, deformities also represent the potent teratogenic effect of fluconazole.

Bérard et al. [47] assessed fluconazole low and high-doses exposure during pregnancy, occurrence of spontaneous abortions, major malformations, and stillbirths. Within a cohort of 320,869 pregnancies were included in the analysis, 226,599 had of major congenital malformations, and 7,832 stillbirths. Most women (69.5\%) received 150 $\mathrm{mg}$ fluconazole (low-dose); the remainder received $>150 \mathrm{mg}$ fluconazole (high-dose). Use of oral fluconazole during earlier pregnancy was associated with increased-risk of spontaneous abortion compared to no exposure. Low exposure to fluconazole during the first trimester did not increased-risk of overall major congenital malformations; however, exposure to high-dose during the first trimester was associated with an increased-risk of cardiac septal closure abnormalities compared to no exposure. No association was found between exposure to fluconazole during pregnancy and risk of stillbirth. Any maternal exposure to fluconazole used during pregnancy may increase risk of spontaneous abortion, and doses higher than $150 \mathrm{mg}$ increase risk of cardiac septal closure abnormalities.

\section{Fluconazole trials in infants and children}

Wilkerson et al. [48] observed that in neonatology, well-designed evidence-based practice guide practitioners. Several large randomized controlled trials have been conducted to explore fluconazole prophylaxis in preterm infants. Despite findings of these studies, practice varies among units. In a recent survey of members of the American Academy of Paediatrics, $34 \%$ of clinicians indicated that they have used antifungal prophylaxis, and only $11 \%$ indicated that a written protocol was in place in their neonatal intensive care units. Sixty-six percent of paediatricians used fluconazole, $59 \%$ oral nystatin, and $21 \%$ intravenous amphotericin $B$. There is the need to elaborate a guideline to optimize and uniform fungal treatment in paediatric patients.

$\mathrm{Ku}$ and Smith [49] observed that determining right dose of drugs is critically important in infants because they have significant differences in physiology affecting drug absorption, distribution, metabolism, and elimination that makes extrapolating dosing-regimens from adults and older children is inappropriate. Specialized analytical techniques, such as the use of dried blood spots, scavenged sampling, population pharmacokinetic analysis, and sparse sampling, have helped investigators better to define doses which maximize efficacy and safety. Use of these methods resulted in successfully clinical trials, and optimized dosing-regimens in this population.

Schware et al. [50] determined optimal therapy in 38 infants; the majority of them were preterm, with a mean birth-weight of 1,120 gram, born at a postmenstrual age of 23 to 38 weeks, and suffering from a systemic Candida mycosis, mostly caused by Candida albicans. Fluconazole treatment ( 5 to $6 \mathrm{mg} / \mathrm{kg}$ daily) was initiated at 5 weeks of life, and the median duration of therapy was 21 days. Clinical cureor improvement-rates were reported in 31 of 38 infants $(81.6 \%)$, and mycological cure-rate was achieved in 25 out 32 infants $(78.1 \%)$. Fluconazole was found to be an effective antifungal therapy, and no adverse-effects were observed. Two infants $(5.2 \%)$ with megauretermegacystis-hydronephrosis syndrome and severe meningoencephalitis showed a mild increase in liver enzymes. Fluconazole therapy is effective for systemic and other forms of candidiasis in these infants.

Manzoni et al. [51] observed that infants in neonatal intensive care units are at high-risk of invasive fungal infection, mostly caused by Candida species. This infection-rate is increasingly, leading to high morbidity- and mortality-rates, and causes frequent neurodevelopmental disabilities in survivors. Fluconazole is the best option to decrease Candida infection, and to prevent disease burden. This antibiotic is a suitable strategy and its efficacy was proven in different studies. Nevertheless, the use of this azole in high-risk preterm infants, admitted in neonatal intensive care, is not yet standardized.

Kaufman [52] observed that a better understanding of adherence factors, molecular diagnostics, and risk-factors are important in treatment of fungal infection. The INT1 gene is associated with enhanced colonization and dissemination in humans. Dissemination is probably caused by test cell adherence and invasion, whereas tissue injury may be related to filamentous formation. PCR technique has demonstrated promise in infants with bloodstream infection. At the time of fungal sepsis, $<28$ weeks of postmenstrual age, thrombocytopenia, and previous exposure to broad-spectrum antibiotic continue to be riskfactors of infection. Fluconazole empiric therapy is still being defined and investigated, in order to prevent fungal infection and colonization in high-risk very-low-birth weight. Multicentre fluconazole clinical 
trials are important to confirm drug safety and efficacy, and empiric treatment to test safety and outcomes is urgently needed.

Viscoli et al. [53] administered fluconazole $(6 \mathrm{mg} / \mathrm{kg}$ daily, administered either orally or intravenously) to 24 children, and all had predisposing HIV-infection, cancer, organ, or bone marrow transplantation, malnutrition, and obstructive uropathy. Two children with fungemia due to Candida parapsilosis required and increased dosage of $12 \mathrm{mg} / \mathrm{kg}$. Clinical and microbiological successes were achieved in 30 of 34 children (88.2\%). Drug-related transaminase increase was observed in only two cases (5.9\%). Fluconazole represents an effective alternative to amphotericin B in treatment of candidiasis in children.

Driessen [54] reported their experience of fluconazole in 21 infants who developed Candida septicaemia and were treated with oral fluconazole over one year. Therapy was continued for at least one week after the first negative culture was observed. Clinical and microbiological cure-rates were similar and accounted in $90.5 \%$ infants. No serious renal, haematological, or hepatic complications were detected; mild hepatotoxicity was evidenced by elevated enzymes in a third of infants. Relapse occurred in only one infant $(4.8 \%)$ who received inadequate fluconazole doses. Fluconazole is a safe and effective alternative for management of systemic candidiasis in infants.

Frattarelli et al. [55] observed that fluconazole was the most antifungal agent studied and show slightly less variability than other antifungal agents in infants. Genetic factors, which affect metabolism of fluconazole, may explain some of the observed variability in drug effects. Amphotericin B deoxycholate is primary nephrotoxic; it also induces electrolyte abnormalities and is to a lesser degree cardiotoxic. Fluconazole toxicity is lower than that of amphotericin B. No sufficient data are available to define the pharmacokinetic profiles, optimal dose, therapy duration, or toxicity for these drugs.

Marchisio and Principi [56] evaluated treatment efficacy of oropharyngeal candidiasis, caused by Candida species including Candida albicans, which occurred in $55 \%$, of children with a mean age of 5 years, suffering from HIV-infection. Fluconazole was given in a mean dose of $3.4 \mathrm{mg} / \mathrm{kg}$ daily (range, 2.0 to 5.6) for a mean duration of 12 days (range, 6 to 28). By the end treatment, $90.0 \%$ of children were clinically cured, $6 \%$ were improved, and $4 \%$ failed to respond. Candida was eradicated in $82 \%$ children. Clinical failure occurred only in children given $3 \mathrm{mg} / \mathrm{kg}$ or less daily dose. After two and four weeks after therapy, clinical cure was confirmed in 88 and $82 \%$ of children, respectively, and infective agents were eradicated in $76 \%$ of children. Six children experienced mild adverse-effects (1 skin rash, 5 mild elevations of liver enzymes). Fluconazole was found to be safe and effective in treating oropharyngeal candidiasis in HIV-infected children.

\section{Fluconazole metabolism}

Godamudunage et al. [57] described effects of azole compounds on cytochrome P450 enzymes (CYP). CYP3A enzymes metabolize up to $50 \%$ of human drugs. While CYP3A4 is the major enzyme in adults, CYP3A7 is the major form in infants aged 6 to 12 months. There are some significant differences between CYP3A4 and CYP3A7. Azoles are effective for treatment of common fungal infections in infants, but can also be rather nonselective CYP inhibitors. In addition, to the clinical relevance of these compounds, azoles constitute a useful series of CYP3A active site probes. These authors evaluated the interactions of different azoles with purified, recombinant human CYP3A4 and
CYP3A7. Fluconazole and flosfluconazole demonstrated unusual binding characteristics to these CYP enzymes. Differences exist between CYP3A7 and CYP3A4 interactions with fluconazole and flosfluconazole. Such differences may underline differential metabolism of common drugs at different life stages and inform dosing in infants versus adults.

Niwa et al. [58] compared effects of five antifungal drugs, fluconazole, itraconazole, micafungin, miconazole, and voriconazole, on CYP2C9-mediated tolbutamide hydroxylation, CYP2C19mediated S-mephenytoin 4'-hydroxylation, and CYP3A4-mediated nifedipine oxidation activities in human liver microsomes. $\mathrm{IC}_{50}$ value against tolbutamide hydroxylation was the lowest for miconazole $(2.0$ $\mu \mathrm{M})$, followed by voriconazole $(8.4 \mu \mathrm{M})$ and fluconazole $(30.3 \mu \mathrm{M})$. Similarly, the $\mathrm{IC}_{50}$ value against S-mephenytoin 4'-hydroxylation was the lowest for miconazole $(0.33 \mu \mathrm{M})$ and fluconazole $(12.3 \mu \mathrm{M})$. These results suggest that miconazole is the strongest inhibitor of CYP2C9 and CYP2C19, followed by voriconazole and fluconazole, whereas micafungin wound not cause clinically significant interactions with other drugs that are metabolized by CYP2C9 or CYP2C19. The $\mathrm{IC}_{50}$ value of voriconazole against nifedipine oxidation was comparable with that of fluconazole and micafungin and higher than that of itraconazole and miconazole. Simulation of inhibition of CYP2C9, CYP2C19, or CYP3A 4-mediated reactions by 5 min preincubation was not observed for any of antifungal drugs, suggesting that these are not mechanismbased inhibitors.

\section{Fluconazole pharmacokinetics in infants}

Leroux et al. [59] studied fluconazole pharmacokinetics in 18 infants with mean postmenstrual, postnatal ages, and birth-weight of 28 weeks +2 days, 13.5 days, and 995 gram, respectively, six infants were born prematurely with a postmenstrual age from 23 to 32 weeks. Ten infants $(55.5 \%)$ were infected by Candida species and one infant had blood and cerebrospinal fluid infected by Candida species. Infants received fluconazole by intravenous infusion; the loading dose was: $25 \mathrm{mg} / \mathrm{kg}$, and the maintenance daily dose was $12 \mathrm{or} 20 \mathrm{mg} / \mathrm{kg}$, and varied according to postmenstrual age, and treatment duration was at least 5 days. Some infants were co-treated with amoxicillin $(\mathrm{N}=5$, $27.8 \%)$, or Vancomycin $(\mathrm{N}=9,50.0 \%)$, or inotropic agents $(\mathrm{N}=6$, $33.3 \%)$, or diuretics $(\mathrm{N}=2,11.1 \%)$ or caffeine $(\mathrm{N}=9,50.0 \%)$. The following pharmacokinetic parameters are expressed as the mean and (range): total body clearance was $0.015 \mathrm{~L} / \mathrm{h} / \mathrm{kg}$ (0.008 to 0.039$)$, distribution volume was $0.91 \mathrm{~L} / \mathrm{kg}$ (0.91 to 0.91$)$, elimination halflife was 40.9 hours (16.2 to 78.4), $\mathrm{AUC}_{0-24 \text { hours }}$ was $491 \mathrm{mg} . \mathrm{h} / \mathrm{L}$ (406 to 572 ), respectively, on the first treatment day. Total body clearance and distribution volume were corrected for birth-weight. At steady-state, all infants reached the target systemic exposure of $\mathrm{AUC}_{0-24 \text { hours }} \geq 400$ mg.h/L, however, 6 infants (33.3\%) did not achieved $\mathrm{AUC}_{0-24 \text { hours }}$ target value $=800 \mathrm{mg} . \mathrm{h} / \mathrm{L}$. Monte Carlo simulations showed that fluconazole target attainment rate increased from 30 to $96 \%$ with the use of $25 \mathrm{mg} /$ $\mathrm{kg}$ loading dose at 24 hours. When using the same maintenance dose, without loading dose, target attainment rate was delayed to 48 hours of treatment. The pharmacokinetic/pharmacodynamic index of AUC/ MIC > 50 for Candida species was achieved in most infants with an MIC breakpoint $\leq 8 \mu \mathrm{g} / \mathrm{ml}$. This issue can be critical in preterm infants who urgently require high and rapidly effective amounts of antifungal drugs owing to a very high severity of systemic candidiasis. These results confirm the necessity of fluconazole loading dose of $25 \mathrm{mg} / \mathrm{kg}$, followed by a maintenance dose of 12 and $20 \mathrm{mg} / \mathrm{kg}$ daily, in infants with $<30$ weeks and $>30$ weeks of postmenstrual age, respectively, these dosing-regimens reduce time needed to reach the target AUC/MIC, 
providing an important therapeutic benefit in such vulnerable patients. Fluconazole was well tolerated in all infants, the loading and dailydoses, higher than those recommended, enable the target AUC to be reached earlier.

Piper et al. [60] performed a prospective, single-centre, open pharmacokinetic and safety-trial consisting of fluconazole loading and maintenance doses of 25 and $12 \mathrm{mg} / \mathrm{kg}$ daily, respectively, intravenous infused. Treatment duration was at least 4 days in 8 infants, aged $<60$ days, with normal hepatic and renal functions. Median (interquartile range) of postmenstrual, postnatal ages and birth-weight were: 37 weeks ( 35 and 38), 16 days (16 and 32), and 2,800 gram (2,000 and $3,100)$, respectively. The following pharmacokinetic parameters are expressed as the median and (interquartile range): total body clearance, distribution volume, elimination half-life, elimination rate constant and AUC $_{0-24 \text { hours }}$ were: $16 \mathrm{~mL} / \mathrm{kg} / \mathrm{h}$ (13 and 20), 1,0 L/kg (0.88 and 1,4), 56 hours (26 and 80), $0.02 \mathrm{~h}^{-1}$ (range, 0.01 to 0.03 ), $479 \mathrm{mg} . \mathrm{h} / \mathrm{L}$ (347 and 496), respectively. Fluconazole total body clearance was highly variable and ranged from 9 to $27 \mathrm{~mL} / \mathrm{kg} / \mathrm{h}$. After the loading dose, 5 of 8 infants (62.5\%) achieved the therapeutic target $\mathrm{AUC}_{0-24 \text { hours }}>400 \mathrm{mg} \cdot \mathrm{h} / \mathrm{L}$, and all infants achieved a 24 -hour trough concentration $>8 \mu \mathrm{g} / \mathrm{ml} . \mathrm{AUC}_{0-24}$ was $493 \mathrm{mg} . \mathrm{h} / \mathrm{L}$ (range, 271 to 499 ), the highest value was observed in infants with elevated serum creatinine $(1.2 \mathrm{mg} / \mathrm{dl})$, and an inverse relationship was observed between fluconazole total body clearance and serum creatinine. Fluconazole is eliminated by glomerular filtration, and this relationship confirms that infants, with renal failure, eliminate fluconazole less rapidly. Elimination half-life, elimination rate constant and $\mathrm{AUC}_{0-24 \text { hours }}$ were: 91.4 hours, $0.010 \mathrm{~h}^{-1}$ and $338 \mathrm{mg} . \mathrm{h} / \mathrm{L}$, respectively, in one infant, supported by extracorporeal membrane oxygenation, and had these values are at the extreme of pharmacokinetic parameters of whole population. These findings suggest that the extracorporeal membrane oxygenation may be responsible for part, of even the majority, of fluconazole clearance. Two infants, suffering from severe anasarca, did not achieve the therapeutic target value. None of infants reached an $\mathrm{AUC}_{0-24 \text { hours }}>800 \mathrm{mg} . \mathrm{h} / \mathrm{L}$, which is the recommended therapeutic target for immune-compromised adults with Candidaemia. All infants tolerated this dosing-regimen well, bud rare serious hepatotoxicity occurred in patients taking fluconazole. However, this toxicity was not related to dosage, total drug exposure, sex, age, it was reversible, and therapy was not discontinued. A loading dose of $25 \mathrm{mg} / \mathrm{kg}$ achieved desired therapeutic target in most critically ill infants.

Murakoso et al. [61] systematically revived fluconazole pharmacokinetic data, and renal function, in infants and adults. Total body clearance normalized by body-surface-area (BSA) $\left(\mathrm{CL}_{\mathrm{BSA}}\right)$ was $1 / 3$ to $1 / 4$ lower than that of adult, but $\mathrm{CL}_{\mathrm{BSA}}$ rapidly increased during the neonatal and infantile periods and attained near adult values at a postmenstrual age of 60 weeks. A significant correlation was observed between $\mathrm{CL}_{\mathrm{BSA}}$ and postmenstrual age in infants: $\mathrm{CL}_{\mathrm{BSA}}$ $\left(\mathrm{ml} / \mathrm{min} / 1.73 \mathrm{~m}^{2}\right)=0.26^{\star}$ postmenstrual age (weeks) - $4.9 \quad(\mathrm{r}=0.68$, $\mathrm{P}$-value $<0.001)$. In addition, developmental time course of glomerular filtration-rate normalized to $\mathrm{BSA}\left(\mathrm{GFR}_{\mathrm{BSA}}\right)$ fitted well with a sigmoidal model with maximum $\mathrm{GFR}_{\mathrm{BSA}}$ of $149 \mathrm{ml} / \mathrm{min} / 1.73 \mathrm{~m}^{2}$. Postmenstrual age was associated with $50 \%$ of $\mathrm{GFR}_{\mathrm{BSA}}$, $\max \left(\mathrm{PMA}_{50}\right)$ of 54 weeks, and the Hill-coefficient=3.7. The following correlation was found between fluconazole clearance and glomerular filtration-rate in infants: clearance $(\mathrm{ml} / \mathrm{min})=0.34^{\star}$ glomerular filtration-rate $(\mathrm{ml} / \mathrm{min})-0.53(\mathrm{r}=0.84$, $\mathrm{P}$-value $<0.001)$. Assuming that fluconazole plasma concentration, required for treating fungal infection, is comparable between children and adults, thus fluconazole doses, for paediatric patients with above given postmenstrual ages may be predicted from adult doses (such as
$100 \mathrm{mg}$ daily) using size-normalized clearance as a scaling factor. The predicted doses for infants were largely within the ranges recommended in prescribing information.

Momper et al. [62] characterized fluconazole population pharmacokinetics, and dosing-regimen, required in 141 preterm infants, suffering from invasive candidiasis, whose postmenstrual, postnatal ages, and birth-weight were: 28.3 weeks (range, 23.7 to 35.1), 23 days (range, 3 to 47 ), and 710 gram (range, 345 to 2,680), respectively. Eight-one infants percent were intubated, $67 \%$ infants were delivered by Caesarean section. Fifty-three percent infants were black or African American, 40\% were white, 5\% were American Indian or Alaska native and $1 \%$ was Asiatic. Infants were treated with fluconazole $6 \mathrm{mg} / \mathrm{kg}$ intravenous infused, or orally administered, twice-weekly for up to 42 days of treatment. Each infant had two pharmacokinetic plasma samples drawn after a single dose taken around the administration time of dose and 3, 5, 7, or 9, hours after dosing, and one sample taken around the administration of the final dose. One-compartment model, and first-order conditional estimation method, was used to describe fluconazole concentration data. The majority of samples ( $\mathrm{N}=368,61 \%)$ were from scavenged samples. The following plasma samples were obtained: scavenged samples (median $4.1 \mu \mathrm{g} / \mathrm{ml}$, range, 0.5 to 14.0 ), and timed samples (median $6.1 \mu \mathrm{g} / \mathrm{ml}$, range, 0.3 to 13.2). The multivariable process started with the elemental components of postmenstrual age (postnatal and gestational ages) rather than postmenstrual age itself. Sequential removal was performed with in reverse order of magnitude of objective function value change seen with the covariate in the invariable screening process. Attempts to remove gestational age (clearance) postnatal age (clearance), and serum creatinine (clearance) each resulted in increases of $>10$ in objective function value. Finally, a model using serum creatinine (clearance) and postmenstrual age (clearance) as a function of gestational and postnatal ages was assessed and performed better than the model with serum creatinine (clearance), gestational age (clearance), and postnatal (clearance) with an objective function value reduction of 37.3 despite having one fewer covariate. The model-estimated absolute oral fluconazole bioavailability was $100 \%$, which is in agreement with prior adult data. No significant relationships were observed between fluconazole clearance or distribution volume and sex, race, ethnicity, intubation, or mode of infant delivery. Population pharmacokinetic parameters were: clearance $\left(\mathrm{L} / \mathrm{h} / \mathrm{kg}^{0.75}\right)=0.0127^{\star}($ serum creatinine concentration $/ 0.8)^{-0.41 *}$ (postmenstrual age $\left./ 28\right)^{2.05}$; distribution volume $(\mathrm{L} / \mathrm{kg})=1.00$; elimination rate constant $\left(\mathrm{h}^{-1}\right)=0.96$; bioavailability $=100 \%$ (where: serum creatinine concentration is in $\mathrm{mg} / \mathrm{dl}$ and postmenstrual age is in weeks). Interindividual variability was estimated as $23 \%$ for clearance, $13 \%$ for distribution volume, and $25 \%$ for bioavailability. A percentage of 98.7 bootstrap data resulted in $\geq 3$ significant digits. The median of bootstrap fixed-effect parameter estimates were within $1 \%$ of population estimates from original data set for all parameters. Using Monte Carlo simulations, fluconazole exposure from dose of $6 \mathrm{mg} / \mathrm{kg}$ twice-daily was assessed. Trough concentration was determined during an 8 week fluconazole course, and predose concentration was compared to a minimum target of $2 \mu \mathrm{g} / \mathrm{ml}$. This threshold was exceeded in $80 \%$ of simulated infants at 1 week, and in $59 \%$ of simulated infants at week 4 of fluconazole prophylaxis. These results are consistent with $95.7 \%$ of the first measured concentration being $>2 \mu \mathrm{g} / \mathrm{ml}$, and with $89.9 \%$ of the overall fluconazole concentrations being $>2 \mu \mathrm{g} / \mathrm{ml}$. Table 1 summarizes fluconazole pharmacokinetic model parameters.

Fluconazole samples used in the Wade et al. [63] study were obtained from two studies enrolling concurrently within Paediatric 
Table 1. Fluconazole pharmacokinetic parameters ${ }^{\mathrm{a}}$ were obtained in 141 preterm infants with mean postmenstrual postnatal ages, and birth-weight of 23 weeks, 24.7 days, and 710 gram. Fluconazole was intravenously infused, or orally administered, at a dose of $6 \mathrm{mg} / \mathrm{kg}$ twice-daily, by Momper $e t$ al. [62]

\begin{tabular}{|c|c|c|c|c|c|}
\hline \multirow[b]{2}{*}{ Parameter } & \multirow[b]{2}{*}{ Point estimate } & \multirow[b]{2}{*}{ Standard error of estimate } & \multicolumn{3}{|c|}{ Bootstrap (Confidence interval) } \\
\hline & & & $2.5 \%$ & Median & $\mathbf{9 7 . 5 \%}$ \\
\hline Distribution volume $(\mathrm{L} / \mathrm{kg})$ & 1.00 & 0.0378 & 0.93 & 1.00 & \\
\hline Clearance $\mathrm{L} / \mathrm{kg}^{0.75}$ & 0.0127 & 0.00033 & 0.012 & 0.0127 & \\
\hline Bioavailability (\%) & 1.00 & 0.065 & 0.86 & 1.00 & \\
\hline Elimination rate constant $\left(\mathrm{h}^{-1}\right)$ & 0.96 & 0.25 & 0.52 & 0.96 & \\
\hline Serum creatinine (clearance) & -0.410 & 0.0498 & -0.53 & -0.41 & \\
\hline Postmenstrual (clearance) & 2.05 & 2.06 & 1.23 & 2.05 & \\
\hline \multicolumn{6}{|c|}{ Interindividual variance (percent coefficient of variation) } \\
\hline Distribution volume & 13 & 61 & 1 & 13 & 18 \\
\hline Clearance & 23 & 29 & 15 & 22 & 50 \\
\hline Bioavailability & 31 & 73 & 1 & 22 & \\
\hline \multicolumn{6}{|c|}{ Residual variance (percent coefficient of variation) } \\
\hline--- & 46 & 27 & 37 & 46 & 51 \\
\hline \multicolumn{6}{|c|}{ Additive value $(\mu \mathrm{g} / \mathrm{ml})$} \\
\hline--- & 0.505 & 0.329 & 0.005 & 0.495 & 0.858 \\
\hline
\end{tabular}

parameters $\mathrm{a}^{\mathrm{a}}=$ confidence interval.

Pharmacology Research Unit. Fifty-five infants were enrolled and had mean postmenstrual, postnatal ages and birth-weight of: 26 weeks (range, 23 to 40), 16 days (range, 1 to 88) and 1,020 gram (range, 451 to $7,120)$, respectively. The infant race was: Caucasian $(50 \%)$, Black $(40 \%)$, other (10\%), and Hispanic (9\%). Twenty-three infants (41.8\%) received prophylaxis from birth, 11 infants $(20.0 \%)$ received prophylaxis with broad-antibiotic exposure, 8 infants $(14.5 \%)$ received prophylaxis for necrotizing enterocolitis, 7 infants $(12.7 \%)$ received treatment for fungal sepsis, 2 infants (3.6\%) received treatment for urinary infection, and 4 infants $(7.2 \%)$ were empirically treated for fungal sepsis. The primary study (study 1) was open label, fluconazole pharmacokinetic study conducted at 8 institutions. Infants were stratified by postmenstrual age (weeks) 23 to 25,26 to 29,30 to 33 , and $\geq 34$, and postnatal age $<14$ and 14 to 119 days. The second study (study 2) was an open label study of a panel of antimicrobial drugs. For both studies, fluconazole dosing was determined by the routine clinical practice and was intravenously infused at dose ranging from 3 to $12 \mathrm{mg} / \mathrm{kg}$ twicedaily. The following information was collected for covariate-analysis: gestational and postnatal ages, weight, urine output ( $\mathrm{ml} / 24$ hours), serum creatinine concentration (SCRT), date of positive Candida cultures, daily-assessment, and respiratory support. Infants in study 1 were randomly assigned to one of two sampling schedules (schedule A included preinfusion, end of infusion, and 1, 6 to 8 , and 20 hours postinfusion; schedule B included preinfusion, end of infusion, and 3, 10 to 12,24 , and 48 hours post-infusion. Monte Carlo simulations replicates of original data were used to explore impact of postnatal and birthgestational ages on pharmacokinetic parameters. For target exposure, $\mathrm{AUC}_{0-24 \text { hours }}=800 \mathrm{mg} \cdot \mathrm{h} / \mathrm{L}$, and fluconazole dose of $800 \mathrm{mg}$ daily ensure that exposure exceeds the pharmacodynamic target of an AUC/ MIC value of $>50$ for Candida species with an $\mathrm{MIC}=8 \mu \mathrm{g} / \mathrm{ml}$ at the clinical and laboratory standard institute sensitivity breakpoint. Table 2 summarizes fluconazole population pharmacokinetic parameters in these infants.

\section{Fluconazole pharmacokinetics in children}

Watt et al. [64] determined fluconazole pharmacokinetics in 21 children with mean postmenstrual, postnatal ages, and body-weight of 40 weeks, 22 days, and $3.4 \mathrm{~kg}$, respectively, receiving extracorporeal membrane oxygenation (ECMO) support, and 19 children, without ECMO support, had mean postmenstrual, postnatal ages, and bodyweight of 39 weeks, 13 days, and $3.2 \mathrm{~kg}$, respectively. Fluconazole samples were obtained from three prospective trials. Study 1 was a single-centre open-label pharmacokinetic study which consisted of 20 children; this antibiotic was administered at a dose of $25 \mathrm{mg} / \mathrm{kg}$ once-weekly for prophylaxis of fungal infection. Study 2 was a single centre pharmacokinetic study in 12 critically ill children, aged $<1$ year, one of whom had ECMO support, and fluconazole loading dose was administered. Study 3 was a multicentre pharmacokinetic study in 8 infants, with postmenstrual and postnatal ages of 23 to 42 weeks, and $<120$ days, respectively, who were treated with fluconazole for prevention or treatment of candidiasis. The following parameters: Interindividual random effects for clearance, distribution volume, and both diagonal and block Omega matrices for covariance were explored. An exponential model for Interindividual variance was used. Bodyweight was incorporated into the base model, before evaluation of other covariates, due to multicollinearity with other clinical covariates. Both linear and allometric scaling of weight was assessed for total body clearance. For distribution volume and intercompartmental clearance parameters, size-based scaling parameters were incorporated using a linear relationship with body-weight. The following covariates were evaluated: ECMO support, volume of blood required to prime ECMO circuit, ratio of blood prime volume to estimated native blood volume of the child, hemofiltration, use of conventional venovenous haemodialysis, serum creatinine concentration, albumin, AST, and ALT levels, post-neonatal age, sex, and race. Fluconazole exhibited timedepended fungistatic activity with prolonged post-antibiotic effect, and efficacy was most associated with AUC/MIC ratio of $>50$. For treatment, target minimum $\mathrm{AUC}_{0-24 \text { hours }}$ of $400 \mu \mathrm{g} . \mathrm{h} / \mathrm{ml}$ was obtained in $90 \%$ of children. This value achieved target AUC/MIC ratio, assuming an $\mathrm{MIC}=8 \mu \mathrm{g} / \mathrm{ml}$, which is the clinical and laboratory standard institute sensitivity breakpoint for all Candida species. Monte Carlo simulations, using parameter estimates from final model, were used to explore dose-exposure relationship. Children were stratified by the presence or absence of ECMO support. Peak and trough concentrations, were used to calculate AUC, for each dosing interval, using linear-up log-down trapezoidal approach, for each of 14 simulate dosing intervals, using the equation for an intermittent infusion. Table 3 shows final population pharmacokinetic parameters, and Table 4 shows Bayesian estimates overall distribution volume and clearance by age group in both children with or without ECMO support.

Cristofoletti et al. [3] observed that higher fluconazole total body clearance is higher in children than in adults, thus it is recommended that 
Table 2. Fluconazole population pharmacokinetic parameters were obtained in 55 infants with mean postmenstrual, postnatal ages and birth-weight of 26 weeks, 16 days, and 1,020 gram, respectively. Fluconazole was intravenously infused at a dose ranging from 3 to $12 \mathrm{mg} / \mathrm{kg}$ twice-daily, by Wade et al. [63]

\begin{tabular}{|c|c|c|c|c|c|}
\hline & & & \multicolumn{3}{|c|}{ Bootstrap CI ${ }^{\mathrm{b}}$} \\
\hline Parameter & Point estimate & $\%$ RSE & $2.5 \%$ & Median & $97.5 \%$ \\
\hline Clearance $(\mathrm{L} / \mathrm{h})$ & 0.015 & 5.9 & 0.013 & 0.015 & 0.017 \\
\hline Distribution volume (L) & 1.024 & 3.8 & 0.944 & 1.021 & 1.096 \\
\hline $\mathrm{Cl}$ (BGA) & 1.737 & 18 & 1.068 & 1.768 & 2.328 \\
\hline $\mathrm{Cl}$ (PNA) & 0.237 & 24 & 0.081 & 0.232 & 0.352 \\
\hline $\mathrm{Cl}$ (SCRT) & -4.896 & -22 & -9.418 & -5.033 & -2.721 \\
\hline SCAV error model & 0.953 & 0.953 & 0.890 & 0.954 & 1.020 \\
\hline \multicolumn{6}{|c|}{ Interindividual variance } \\
\hline Omega 1 & 0.11 & 0.11 & 0.064 & 0.104 & 0.156 \\
\hline Omega 1 & 0.014 & 0.014 & 0.033 & 0.010 & 0.055 \\
\hline Omega 3 & 0.057 & 0.057 & 0.025 & 0.055 & 0.095 \\
\hline \multicolumn{6}{|c|}{ Residual variance } \\
\hline Sigma 1 & 0.027 & 31 & 0.004 & 0.025 & 0.041 \\
\hline Omega 2 & 0.04 & 102 & 0.004 & 0.042 & 0.300 \\
\hline Omega 3 & 0.081 & 34 & 0.021 & 0.076 & 0.128 \\
\hline Omega 4 & 0.023 & 143 & 0.0000 & 0.021 & 0.120 \\
\hline
\end{tabular}

$\%$ RSE=percent relative to the standard error of estimate equals the standard error divided by parameter estimates time 100 . ${ }^{\mathrm{c}} 95 \%$ confidence interval lower and upper bounds and median as determined from a parametric bootstrap of 1,000 replicates. BGA=gestational age at birth. PNA=postnatal age. $\mathrm{Cl}(\mathrm{SCRT})=\mathrm{Creatinine}$ concentration=1 if SCRT $>1 \mathrm{mg} / \mathrm{dl}$, creatinine concentration $=0$ if SCRT $\leq 1 \mathrm{mg} / \mathrm{kg}$. Clearance Sigma $1=$ sigma 1 nonscavenged PK sample. Sigma $2=$ sigma 2 nonscavenged PK sample. Sigma $3=$ sigma 3 scavenged PK sample. Sigma 4=sigma 4 scavenged PK sample. PK sample=pharmacokinetic sample.

Table 3. Fluconazole population pharmacokinetic parameters were obtained in 59 children with mean postnatal, postmenstrual, and body-weight of 41 weeks, 22 days, and 3.4 kg, respectively. Fluconazole was administered at different doses (see text). No distinction was made from children with or without ECMO support, and all children are enclosed in the analysis, by Watt et al. [64]

\begin{tabular}{|c|c|c|c|c|c|}
\hline & & & \multicolumn{3}{|c|}{ Bootstrap (confidence interval) } \\
\hline Parameters & Point estimate & \%REE & $2.5 \%$ & Median & $97.5 \%$ \\
\hline \multicolumn{6}{|c|}{ Fixed effects } \\
\hline Distribution volume (L/kg) & 0.93 & 5.8 & 0.83 & 0.93 & 1.06 \\
\hline Clearance $(\mathrm{L} / \mathrm{h} / \mathrm{kg})$ & 0.019 & 5.6 & 0.017 & 0.019 & 0.021 \\
\hline Coef. ECO DV & 1.39 & 7.8 & 1.17 & 1.39 & 1.63 \\
\hline Exp. Cre. on $\mathrm{Cl}$ & -0.29 & 9.9 & -0.41 & -0.29 & -0.24 \\
\hline \multicolumn{6}{|c|}{ Random effects } \\
\hline $\begin{array}{l}\text { Distribution volume } \\
\text { Interindividual CV (\%) }\end{array}$ & 22.2 & 28.6 & 14.7 & 21.5 & 27.7 \\
\hline $\begin{array}{c}\text { Clearance Interindividual } \\
\text { variability CV }(\%)\end{array}$ & 33.2 & 21.3 & 25.0 & 32.6 & 39.2 \\
\hline $\begin{array}{l}\text { Residual proportional error, } \\
\text { CV (\%) }\end{array}$ & 15.3 & 13.1 & 13.0 & 15.3 & 16.9 \\
\hline
\end{tabular}

$\% \mathrm{REE}=$ percent residual standard error. $\mathrm{CV}=$ coefficient of variation. Coef. ECO DV=coefficient for ECMO on distribution volume. Exp. Cre. on $\mathrm{Cl}=\mathrm{exponent}$ for creatinine on clearance. $\mathrm{ECMO}=$ extracorporeal membrane oxygenation.

Table 4. Bayesian estimates of fluconazole distribution volume and total body clearance overall and grouped by age in children with or without ECMO support. Children, with ECMO support, $(\mathrm{N}=21$ ) had mean postmenstrual, postnatal ages, and body-weight of 42 weeks, 113 days, and $4.2 \mathrm{~kg}$, respectively. Children ( $\mathrm{N}=19)$ without ECMO support had mean postmenstrual, postnatal ages, and body-weight of 39 weeks, 13 days, and $3.2 \mathrm{~kg}$, respectively. Fluconazole was administered at different doses (see text). Figures are the median and (range), by Watt $e t$ al. [64]

\begin{tabular}{|c|c|c|}
\hline Distribution volume and clearance arranged by age & Distribution volume $(\mathrm{L} / \mathrm{kg})$ \\
\hline & $1.5(1.3$ to 1.8$)$ & $0.96(0.55$ to 1.4$)$ \\
\hline 0 to 30 days & $1.2(0.91$ to 1.6$)$ & $0.83(0.72$ to 1.00$)$ \\
\hline 31 days to 2 years & $1.1(0.81$ to 1.5$)$ & $-1.3(0.81$ to 1.8$)$ \\
\hline$>2$ to 17 years & Total body clearance $(\mathrm{L} / \mathrm{h} / \mathrm{kg})$ & $0.93(0.55$ to 1.40$)$ \\
\hline All children & $0.018(0.013$ to 0.043$)$ & $0.018(0.008$ to 0.042$)$ \\
\hline & $0.022(0.011$ to 0.039$)$ & $0.017(0.008$ to 0.029$)$ \\
\hline 0 to 30 days & $0.014(0.013$ to 0.029$)$ & - \\
\hline All children & $0.018(0.011$ to 0.043$)$ & \\
\hline
\end{tabular}

$\mathrm{ECMO}=$ extracorporeal membrane oxygenation. 
higher relative dose on $\mathrm{mg} / \mathrm{kg}$ basis should be administered to children in order to achieve similar systemic exposure to adults. These authors validated the adult whole-body physiologic based pharmacokinetic model, and absorption models, its paediatric counterpart was developed by means of changing the system component of the model to reflect the specific anatomy, physiology, and biochemistry of the paediatric group under study. This approach requires some fundamental assumptions: (1) the drug undergoes same metabolic pathway in adults and paediatrics; (2) the model structure is similar in both populations; and (3) unless otherwise stated, variability in terms of anatomy, physiology, and biochemistry is considered similar. Once a preliminary first-in-paediatric dose is defined using modelling and simulation tools, a subsequent confirmatory pharmacokinetic study is necessary to assess whether systemic exposures, and consequently, similar therapeutic responses in adults and children would be indeed similar. A relative bioavailability study, enrolling healthy adult volunteers, was conducted to compare the paediatric formulation with approved adult drug product. There is often little or no consideration given to differences in gastrointestinal between adult and paediatric patients. Fluconazole is cleared primarily by kidney, with approximately $80 \%$ of the administered dose appearing in the urine as unchanged drug. The renal clearance value reported after intravenous fluconazole administration was estimated from total body clearance (i.e. nonrenal clearance $=$ total body clearance - renal clearance). Table 5 shows fluconazole properties taken from the literature or estimated according to the method described in the table, and absorption of 2 fluconazole doses in children and adults.

Lee et al. [65] evaluated fluconazole pharmacokinetics in 26 children, aged 5 to 15 years, with normal renal function who received treatment for cancer. Fluconazole was intravenously infused at doses of 2 , or 4 , or $8 \mathrm{mg} / \mathrm{kg}$ for 7 days. Fluconazole showed linear first-order kinetics over the dosage range tested and during multiple dosing. After the first-dose, mean total body clearance, distribution volume and elimination half-life were: $22.8+2.3 \mathrm{ml} / \mathrm{min}, 0.87+0.06 \mathrm{~L} / \mathrm{kg}$, and $16.8+1.1$ hours, respectively. Similarly, after the last dose, total body clearance, distribution volume, and elimination half-life were: $19.4+1.3$ $\mathrm{ml} / \mathrm{min}, 0.84+0.04 \mathrm{~L} / \mathrm{kg}$, and $18.1+1.2$ hours, respectively. Following a dose of $8 \mathrm{mg} / \mathrm{kg}$, peak and trough serum concentrations were: $9.5+0.4$ and $2.7+0.5 \mu \mathrm{g} / \mathrm{ml}$, respectively, and AUC0- $\infty$ was $186+16 \mu \mathrm{g} . \mathrm{h} / \mathrm{ml}$. Fluconazole renal clearance was $65+5 \%$ of the total body clearance and demonstrated the predominantly renal excretion of this drug.

\section{Mechanisms of bacteria-resistance to fluconazole}

Candida lusitaniae is usually susceptible to echinocandins. $\beta$-1,3-glucan synthase encoded by FKS genes which is the target of echinocandins. A few missense mutations in Candida lusitaniae FKS1 hot-spot 1 (HS1) have been reported. Asner et al. [66] reported the rapid emergence of antifungal-resistant in Candida lusitaniae isolated during therapy with amphotericin B, caspofungin, and azoles for treatment of persistent Candidaemia in an immunocompromised child with severe enterocolitis and visceral adenoviral disease. As documented, from restriction fragment length polymorphism, random amplified, and polymorphic DNA analysis, five Candida lusitaniae isolates examined were related to each other. From antifungal susceptibility and molecular analysis, 5 different profiles were obtained. These profiles included the following: profile 1 (caspofungin $\mathrm{MIC}=0.5$ $\mu \mathrm{g} / \mathrm{ml}$, fluconazole $\mathrm{MIC}=0.25 \mu \mathrm{g} / \mathrm{ml}$ ), determined while the child was being treated with liposomal amphotericin B for 3 months; profile 2 (fluconazole $\mathrm{MIC}=0.25 \mu \mathrm{g} / \mathrm{ml}$, caspofungin $\mathrm{MIC}=4 \mu \mathrm{g} / \mathrm{ml}$ ) while the child was being treated with caspofungin for 2 weeks, profile 3 (caspofungin $\mathrm{MIC}=0.5 \mu \mathrm{g} / \mathrm{ml}$, fluconazole $\mathrm{MIC}=32 \mu \mathrm{g} / \mathrm{ml}$ ), while the child was being treated with azoles and caspofungin initially followed by azoles alone for one week, profile 4 (caspofungin $\mathrm{MIC}=8 \mu \mathrm{g} / \mathrm{ml}$ fluconazole $\mathrm{MIC}=8 \mu \mathrm{g} / \mathrm{ml}$ ), while the child was being treated with both drugs for 3 weeks, and profile 5 (amphotericin B MIC=0.125 $\mu \mathrm{g} / \mathrm{ml}$, caspofungin $\mathrm{MIC}=8 \mu \mathrm{g} / \mathrm{ml}$ ), while the child caspofungin-resistance was associated was being treated with amphotericin $\mathrm{B}$ and fluconazole for 2 weeks. Caspofungin-resistance was associated with resistance not only to micafungin and anidulafungin but also to amphotericin $B$. Analysis of caspofungin-resistance revealed 3 novel FKS1 mutations in caspofungin-resistant isolates (S638Y in profile 2, S631Y in profile 4, and S638P in profile 5). While S638Y and -P are within HS1, S631Y is close proximity to this domain but was confirmed to confer candinresistance using a site-directed mutagenesis approach. Fluconazole-

Table 5. Parameter values, used for fluconazole simulations in the simpcyp simulator, and intestinal absorption-rate in 4 tracts of small intestine, by Cristofoletti et al. [3]

\begin{tabular}{|c|c|c|c|}
\hline Molecular weight & Hydrophilicity & Tissue-plasma partition coefficient & -- \\
\hline 306.27 & 0.5 & 2.03 & --- \\
\hline Model & $\begin{array}{l}\text { Peff.man } \\
\left(10^{-4 \mathrm{~cm} / \mathrm{sec}}\right)\end{array}$ & Maximum supersaturation ratio & Precipitation rate constant $\left(\mathrm{h}^{-1}\right)$ \\
\hline Absorption and metabolism & 4.3 & 1 & 0 \\
\hline Model & Distribution volume at steady-state $(\mathrm{L} / \mathrm{kg})$ & Fraction unbound in plasma & Blood to plasma repartition coefficient \\
\hline Physiological basis pharmacokinetics & 0.7 & 0.88 & 0.83 \\
\hline $\begin{array}{l}\text { Intravenous clearance } \\
(\mathrm{L} / \mathrm{h})\end{array}$ & $\begin{array}{l}\text { Non-renal clearance } \\
(\mathrm{L} / \mathrm{h})\end{array}$ & $\begin{array}{l}\text { Renal clearance } \\
(\mathrm{L} / \mathrm{h})\end{array}$ & *Inulin clearance \\
\hline 1.4 & 0.3 & 1.1 & 0.09 \\
\hline \multicolumn{4}{|c|}{ Fluconazole absorption-rate from 4-tracts of small intestine of children and adults } \\
\hline Duodenum & Jejunum & Ileum first-tract & Ileum fourth-tract \\
\hline \multicolumn{4}{|c|}{$200 \mathrm{mg}$ children } \\
\hline 2.4 & 20.0 & 8.9 & 5.3 \\
\hline \multicolumn{4}{|c|}{$200 \mathrm{mg}$ adults } \\
\hline 1.7 & 9.0 & 4.8 & 2.9 \\
\hline \multicolumn{4}{|c|}{$400 \mathrm{mg}$ children } \\
\hline 4.5 & 25.3 & 11.8 & 7.3 \\
\hline \multicolumn{4}{|c|}{$400 \mathrm{mg}$ adults } \\
\hline 4.7 & 16.6 & 8.6 & 5.2 \\
\hline
\end{tabular}

Peff.man=Effective permeability in humans. ${ }^{*} \mu 1 / \mathrm{min} / \mathrm{mg}$ microsomial protein. 
resistance could be linked with overexpression of major facilitator gene 7 (MFS7) in Candida lusitaniae profiles 2 and 4 and was associated with resistance to 5-fluoocytosine. While candins or azole-resistance followed monotherapy, multidrug antifungal-resistance emerged during combined therapy.

Kovacicova et al. [67] tested antifungal susceptibility of 262 bloodstream yeast isolates (164 Candida albicans, 88 non-albicans Candida species, and 10 non-Candida yeasts) recovered from 169 infants undergoing surgery, admitted to intensive care unit patients and cancer children (mixed infant population) were treated with fluconazole in order to correlate in-vitro fluconazole-resistance with outcome of in-vivo fungemia. There were no Candida albicans stains resistant to fluconazole. Nine of 11 strains of Candida krusei were resistant to fluconazole $(\mathrm{MIC}=64 \mu \mathrm{g} / \mathrm{ml}), 2$ exceptions showed dose-dependentresistance, and fluconazole MICs $=6$ and $32 \mu \mathrm{g} / \mathrm{ml}$. However, only 2 of 29 Candida glabrata strains (6.9\%) were fully fluconazole-resistant (MIC $\geq$ $64 \mu \mathrm{g} / \mathrm{ml}$ ), 27 being susceptible with MICs $=0.5$ and $8 \mu \mathrm{g} / \mathrm{ml}$. Apart from 9 Candida krusei, 2 Candida glabrata, 2 Candida parapsilosis, and 1 Candida tropicalis strains were fully fluconazole-resistant. Among 88 non-albicans Candida species, $17.0 \%$ were fluconazole-resistant. In 161 patients treated with fluconazole, outcomes of patients infected were compared with fluconazole-resistant versus fluconazole-susceptible yeasts. Attributable mortality-rate was significantly higher (19.0 versus $8.6 \%$, P-value $<0.01)$ in patients infected with fluconazole-resistant yeasts.

Marchaim et al. [68] reported increased occurrence of secondary fluconazole-resistance, analysis of risk-factors thereof, and described management of fluconazole-refractory vaginitis. Twenty-five women with vaginitis were enrolled and they had fluconazole-resistant to Candida albicans (MIC $\geq 2 \mu \mathrm{g} / \mathrm{ml}$ ). Study cohort consisted mainly of married, insured white aged $>12$ years having formal education averaged or above socioeconomic status. Median fluconazole $\mathrm{MIC}=8$ $\mu \mathrm{g} / \mathrm{ml}$ (range, 2 to 128). Risk-factors for mycological failure included increased fluconazole consumption (P-value $=0.03$ ) in 16 of 25 women (72.7\%) exposed to low-dose weekly maintenance therapy. All women were successfully treated, although treatment was difficult and often prolonged. Vaginitis caused by fluconazole-resistant Candida albicans was previously considered rare. All women had fluconazoleconsumption in the previous 6 months. Management of fluconazolerefractory disease is extremely difficult with limited options, and new therapeutic modalities are needed.

Krcmery and Barnes [69] observed that non-albicans Candida causes 35 to $65 \%$ of all Candidaemias in hospitalized patients, and occurs more frequently in diseased patients, and appears in children with a frequency of 1 to $35 \%$. The proportion of non-albicans Candida species is increased from 10 to $40 \%$ to 35 to $65 \%$ in the last two decades. The most common non-albicans Candida were: Candida Parapsilosis (20 to $40 \%$ of all Candidaemias), Candida tropicalis (10 to $30 \%$ ), Candida krusei (10 to $35 \%$ ), and Candida glabrata (5 to $40 \%$ ). At least two other species were emerging: Candida lusitaniae and Candida guilliermondii causing infection in 2 to $8 \%$ and 1 to $5 \%$, respectively. Other non-albicans Candida species, such as Candida rugosa, Candida kefyr, Candida stellatoidea, Candida norvegensis, and Candida famata are rare. Mortality-rate due to non-albicans Candida species is similar to that caused by Candida albicans, and ranges from 15 to $35 \%$. However, there are differences in both overall and attributable mortality-rate among species: the lowest mortality-rate is associated with Candida parapsilosis, the highest with Candida tropicalis and Candida glabrata
(40 to $70 \%$ ). There are several specific risk-factors for particular nonalbicans Candida species: Candida parapsilosis is related to foreign body insertion, infants with hyper-alimentation; Candida krusei to azole prophylaxis and along with Candida tropicalis to neutropenia and bone marrow transplant recipients; Candida glabrata to azole prophylaxis, surgery, and urinary or vascular catheters; Candida lusitaniae and Candida guilliermondii to previous amphotericin B or nystatin use; and Candida rugosa to burns. Antifungal susceptibility varies significantly, in contrast to Candida albicans: some non-albicans Candida species are inherently or secondarily fluconazole-resistant; $75 \%$ of Candida krusei isolates, $35 \%$ of Candida glabrata, 10 to $25 \%$ of Candida tropicalis, and Candida lusitaniae. Therefore, "species directed" therapy should be administered for fungemia according to the species identified-resistant or tolerant Candida species (Candida lusitaniae and Candida guilliermondii). In-vitro susceptibility testing should be performed for most species of non-albicans Candida in addition to remove any foreign body to optimize management. Several authors observed that antifungal consumption prior exposure to fluconazole increased the risk of infection. These findings suggest the need for a closer look at fluconazole therapy as possible risks for development of fungal infections and to optimize therapy [68,70-73].

\section{Discussion}

Fluconazole is the most potent antifungal agent, and it used in cancer therapy. All susceptible fungi are capable of deaminating flucytosine to 5-fluorouracil a potent antimetabolite that is used in cancer chemotherapy. Fluorouracil is metabolized first to 5-fluorouracilribose monophosphate by the enzyme uracil phosphoribosyl transferase. 5- Fluorouracil-ribose monophosphate is then either incorporated into RNA (via synthesis of 5-fluorourine triphosphate) or metabolized to 5-fluoro-2'-deoxyuridine-5'-monophosphate, a potent inhibitor of thymidylate synthase, ultimately inhibiting DNA synthesis. The selective action of flucytosine is due to the lack of cytosine deaminase in mammalian cell, which prevents metabolism of fluorouracil. Fluconazole is active against several Candida species, Blastomyces dermatitis, Human capsulatum, and Coccidioides species, Paracoccidioides brasiliensis, and ringworm fungi (dermatophytes). Fluconazole is also active against Aspergillus species, Scedosporium apiospermun (Pseudallescheria boydii), Fusarium, and Sporothrix schenckii, but these fungi are intermediate in susceptibility. Fluconazole is almost completely absorbed from the gastrointestinal-tract (mainly from the small intestine) [3-6], and it is formulated for orally dosing [2]. This drug diffuses in all body tissues where reaches effective concentration, and tissue-plasma partition coefficient is 2.03 [3]. Penetration into cerebrospinal fluid is good [38,39] and successfully cured meningitis caused fungemia [40,41], and is the drug of choice for treatment of meningitis caused by Coccidioidal meningitis [2]. Fluconazole also migrates into breast-milk in significant amounts, the estimated relative infant dose is $17 \%$ of the maternal dose, and drug half-life is 30 hours in breast-milk, thus it is longer than that of found in healthy volunteers [42]. Fluconazole was found to be effective and safe in infants and children [7-13], however, it causes birth-defects when is administered at high dose ( $400 \mathrm{mg}$ daily) in pregnant women [43-47]. This antibiotic was successfully used for prophylaxis, it decreased Candida albicans and non-Candida albicans infection and colonization [14-18], and it was confirmed to be a suitable option for fungal infection treatment [19-29] either in infants and children. Fluconazole is metabolized by CYP3A enzymes, while CYP3A4 is the major enzyme in adults; CYP3A7 is the major form in infants $[57,58]$. 
Fluconazole interacts with drugs which are metabolically cleared by CYP3A enzymes, and enhances or inhibits drug effects, metabolism, and pharmacokinetics [30-37]. Fluconazole therapy was found to be effective and safe for systemic forms of candidiasis in infants and children [48-56]. Fluconazole pharmacokinetics have been extensively studied in infants [59-63] and children [3,64]. In infants, half-life is 40 to 60 hours, whereas it is $<20$ hours in children. Such a difference is attributable to reduced renal function in infants, as this drug is mainly eliminated by glomerular filtration, and renal function increases with infant maturation. In children, renal and non-renal clearances are 1.1 and $0.3 \mathrm{~L} / \mathrm{h}$, respectively, indicating the prevalence of renal elimination pathway [3]. Distribution volume is high, it is about $1 \mathrm{~L} / \mathrm{kg}$, indicating that fluconazole distributes in all body tissues, and the tissue-plasma partition coefficient is 2.03 [3]. Different Candida species, including non-albicans Candida, may become fluconazole-resistant [66-70], and resistance-rate is specie-depended [69]. Such a resistance causes patient serious adverse-effects including mortality [69], and mortalityrate due to resistant-Candida albicans, and non-albicans Candida species, ranges from 15 to $35 \%$ [69]. Fluconazole-resistance may be caused by gene mutation, this has been observed in Candida lusitaniae, and the mutated gene causing resistance is FKS [66]. Another mechanism of resistance is augmented MIC of fluconazole in various Candida species, and this is particular true for Candida Kruse whose $\mathrm{MIC}=64 \mu \mathrm{g} / \mathrm{ml}$ [67]. Some authors observed that azole consumption determines fluconazole-resistance in various Candida species, thus a closer look at fluconazole therapy reduces resistance-rate [68,7073], and optimizes therapy with this drug [69]. Rogers and Krysan [2] reviewed mechanisms of fungal-resistance. In Candida albicans, azole-resistance can be due in part to accumulation of mutations in ERG11, the gene encoding the azole target 14-a-sterol demethylase. Increased azole efflux, caused by overexpression of $\mathrm{ABC}$, and/or major facilitator superfamily transporters impart azole-resistance in Candida albicans and Candida glabrata. Overexpression of these genes is due to activating mutations in genes encoding their transcriptional regulators. Mutation of C5,6 sterol desaturase gene ERG3 also can increase azoleresistance in some species [74]; such mutations prevent formation of the toxic product 14a-methyl-3,6-diol form 14a-methylfecosterol; the resulting accumulation of $14 \alpha$-methylfecosterol produces functional membranes and overcomes the azole effect. Increased production of 14- $\alpha$-sterol demethylase due to over expression of EGR11 occurs owing to activating mutations in the gene encoding its transcriptional regulator Upc2. Primary azole-resistance has been described in some isolates of azole fumigatus with increased azole export and decreased ergosterol content, but the clinical significance is unknown. Decreased fluconazole-susceptibility has been described in Candida neoformans isolated from patients with AIDS failing prolonged therapy.

In conclusion, Fluconazole is the most potent antifungal agent; its mechanism. All susceptible fungi are capable of deaminating flucytosine to 5-fluorouracil a potent antimetabolite that is used in cancer chemotherapy. Fluorouracil is metabolized first to 5-fluorouracil-ribose monophosphate by the enzyme uracil phosphoribosyl transferase. 5Fluorouracil-ribose monophosphate is then either incorporated into RNA (via synthesis of 5-fluorourine triphosphate) or metabolized to 5-fluoro-2'-deoxyuridine-5'-monophosphate, a potent inhibitor of thymidylate synthase, ultimately inhibiting DNA synthesis. Fluconazole is successfully used in the prophylaxis and treatment of fungal infections. Fluconazole is almost completely absorbed from the gastrointestinaltract (mainly from the small intestine), and it is formulated for orally dosing. This drug diffuses in all body tissues, including cerebrospinal fluid and breast-milk, and it is successfully used for treating bacterial meningitis infections. Fluconazole was found to be effective and safe in infants and children, however, it causes birth-defects when it is administered at high dose (400 mg daily) in pregnancy. Fluconazole is metabolized by CYP3A enzymes, and interacts with drugs which are metabolically cleared by CYP3A enzymes, thus enhances or inhibits their effects, metabolism, and pharmacokinetics. Fluconazole pharmacokinetics have been extensively studied in infants and children; its half-life is 40 to 60 hours in infants, whereas it is $<20$ hours in children. Such a difference is attributable to reduced renal function in infants compared to that of children, as this drug is mainly eliminated by glomerular filtration, and renal function increases with infant maturation. In children, renal and non-renal clearances are 1.1 and 0.3 $\mathrm{L} / \mathrm{h}$, respectively, indicating the prevalence of renal route. Distribution volume is high, it is about $1 \mathrm{~L} / \mathrm{kg}$, indicating that fluconazole distributes in all body tissues, and the tissue-plasma partition coefficient is 2.03 . Different Candida species, including non-albicans Candida, may become fluconazole-resistant, and resistance mechanisms are due to gene mutation and/or increased MIC values for fluconazole. Azole consumption causes fluconazole-resistance; this consideration must be taken into consideration in order to avoid infection-risks and optimizing therapy, keeping in mind that fluconazole-resistance causes serious adverse-effects including mortality-rate.

\section{Conflict of interests}

The authors declare no conflicts of financial interest in any product or service mentioned in the manuscript, including grants, equipment, medications, employments, gifts, and honoraria.

This article is a review and drugs have not been administered to men or animals.

\section{Acknowledgments}

The author thanks Dr. Patrizia Ciucci and Dr. Francesco Varricchio, of the Medical Library of the University of Pisa, for retrieving the scientific literature.

\section{References}

1. Neonatal Formulary (2020). Eight Edition, Oxford University Press. Great Clarendon Street, Oxford, OX2, 6DP, UK, pp: 319-321.

2. Rogers PD, Krysan DJ (2018) Antifungal Agents. In the Goodman \& Gilman's The Pharmacological Basis of Therapeutics. $13^{\text {th }}$ Edition. Brunton LL, Hilal-dandan, Knollmann BC, editors. Mc Graw Hill, New York, pp: 1092-1096.

3. Cristofoletti R, Charoo NA, Dressman JB (2016) Exploratory investigation of the limiting steps of oral absorption of fluconazole and ketoconazole in children using an in silico pediatric absorption model. J Pharm Sci 105: 2794-2803.

4. Schäfer-Korting M (1993) Pharmacokinetic optimisation of oral antifungal therapy. Clin Pharmacokinet 25: 329-341. [Crossref]

5. Nahata MC, Brady MT (1995) Pharmacokinetics of fluconazole after oral administration in children with human immunodeficiency virus infection. Eur J Clin Pharmacol 48: 291-293.

6. Gupta AK, Cooper EA, Montero-Gei F (2003) The use of fluconazole to treat superficial fungal infections in children. Dermatol Clin. 21: 537-42. [Crossref]

7. Castagnola E, Jacqz-Aigrain F, Kaguelidoub F, Maragliano R, Stronatic M, et al. (2012) Fluconazole use and safety in the nursery. Early Hum Dev 88: 11-15.

8. Murata K, Oshima J, Sugiyama N, Sugiyama N, Houzama K, et al. (2018) Efficacy and safety of fluconazole in infants including neonates a special drug use-results survey. Jpn J Chemother 66: 600-605. [Crossref]

9. Lee J, Kim H-S, Shin SH, Choi CW, Kim E-K, et al. (2013) Efficacy and safety of fluconazole prophylaxis in extremely low birth-weight infants: Multicenter pre-post cohort study. BMC Pediatrics 16: 67. 
10. Gürpinar AN, Balkan E, Kiliç N, Kiriştioğlu I, Avşar I, et al. (1997) Fluconazole Treatment of Neonates and Infants with Severe Fungal Infections. J Int Med Res 25: 214-218.

11. Fasano C, O'Keeffe J, Gibbs D (1994) Fluconazole treatment of neonates and infants with severe fungal infections not treatable with conventional agents. Eur J Clin Microbiol Inf Dis 13: 351-354

12. Schaware R, Penk A, Pittrow L (2002) Administration of fluconazole in children below 1 year of age. Mycoses 42: 3-16. [Crossref]

13. Novelli V, Holzel H(1999) Safety and tolerability of fluconazole in children. Antimicrob Agents Chemother 43: 1955-1960.

14. Autmizguine J, Smith PB, Prather K, Bendel C, Natarajan G, et al. (2018) Effect of fluconazole prophylaxis on Candida fluconazole susceptibility in premature infants. $J$ Antimicrob Chemother 73: 3482-3487.

15. Ericson JE, Kaufman DA, Kicklighter SD, Bhatia J, Testoni D, et al. (2016) Fluconazole prophylaxis for the prevention of candidiasis in premature infants: A meta-analysis using patient-level data. Clin Infect Dis 63: 604-610. [Crossref]

16. Kaufman D, Boyle R, Hazen KC, Patrie JT, Robinson M, et al. (2001) Fluconazole prophylaxis against fungal colonization and infection in preterm infants. $N \mathrm{Engl} J \mathrm{Med}$ 345: 1660-1666.

17. Weitkamp J-H, Ozdas A, LaFleur B, A L Potts AL (2008) Fluconazole prophylaxis for prevention of invasive fungal infections in targeted highest-risk preterm infants limits drug exposure. $J$ Perinatol 28: 405-411.

18. Aziz M, Patel AL, Losavio J, Iyengar A, Berven M, et al. (2010) Efficacy of fluconazole prophylaxis for prevention of invasive fungal infection in extremely low birth-weight infants. Pediatr Infect Dis J 29: 352-356. [Crossref]

19. Gürpinar AN, Balkan E, Kiliç N, Kiriştioğlu I, Avşar I, et al. (1997) Fluconazole treatment of neonates and infants with severe fungal infections. J Int Med Res 25: 214 218.

20. Charlier C, Hart E, Lefort A, Ribaud P, Dromer F, et al. (2006) Fluconazole for the management of invasive candidiasis: Where do we stand after 15 years? J Antimicrob Chemother 57: 384-410.

21. Kakourou T, Uksal U, European Society for Pediatric Dermatology (2010) Guidelines for the Management of Tinea Capitis in Children. Pediatr Dermatol 27: 226-228.

22. Iosifidis E, Papachristou S, Roilides E (2018) Advances in the treatment of mycoses in pediatric patients. J Fungi (Basel) 4: 115

23. Ben-Ami R (2018) Treatment of invasive candidiasis: A narrative review. treatment of invasive candidiasis: a narrative review. J Fungi (Basel) 4: 97. [Crossref]

24. Michelerio A, Barruscotti S, Bossi G, Brazzelli V (2018) Pediatric old world cutaneous leishmaniasis treated with oral fluconazole: A case series. Pediatr Dermatol 35: 384387.

25. Watt KM, Cohen-Wolkowiez M, Barrett JS, Sevestre M, Zhao P, et al (2018) Physiologically based pharmacokinetic approach to determine dosing on extracorporeal life support: fluconazole in children on ecmo. CPT Pharmacometrics Syst Pharmacol 7: 629-637.

26. Sesmero JMM, Sedano FJF, García TM, Brussi MM, et al. (2005) Funga chemoprophylaxis with fluconazole in preterm infants. Pharm World Sci 27: 475-477.

27. Fox LM, Wilder AG, Foushee JA (2013) Physical compatibility of various drugs with neonatal total parenteral nutrient solution during simulated y-site administration. $\mathrm{Am} \mathrm{J}$ Health Syst Pharm 70: 520-524. [Crossref]

28. Nwaroh E, Jupp J, Jadusingh E, Guilcher G (2018) Clinical impact and management of fluconazole discontinuation on sirolimus levels in bone marrow transplant patients. $J$ Oncol Pharm Pract 24: 235-238.

29. Liu N-N, Köhler JR (2015) Antagonism of fluconazole and a proton-pump inhibitor against candida albicans. Antimicrob Agents Chemother 60: 1145-1147.

30. Levin TT, Cortes-Ladino A, Weiss M, Palomba ML (2008) Life-threatening serotonin toxicity due to a citalopram-fluconazole drug interaction: case reports and discussion. Gen Hosp Psychiatry 30: 372-377. [Crossref]

31. Black DJ, Kunze KL, Wienkers LC, Gidal BE, Seaton TL, et al. (1996) warfarinfluconazole. ii. a metabolically based drug interaction: in vivo. Studies Drug Metab Dispos 24: 422-428.

32. Yang J, Atkins WM, Isoherranen N, Paine MF, Thummel KE (2012) Evidence of CYP3A allosterism in vivo: analysis of interaction between fluconazole and midazolam. Clin Pharmacol Ther 91: 442-449. [Crossref]
33. Finch CK, Green CA, Timothy H Self TH (2002) Fluconazole-carbamazepine Interaction. South Med J 95: 1099-10100.

34. Hilbert J, Messig M, Kuye O, Friedman H (2001) Evaluation of interaction between fluconazole and an oral contraceptive in healthy women. Obstet Gynecol 98: 218-223. [Crossref]

35. Blum RA, Wilton JH, Hilligoss DM, Gardner MJ, Henry EB, et al. (1991) Effect of fluconazole on the disposition of phenytoin. Clin Pharmacol Ther 49: 420-425.

36. Cobb MN, Desai J, Brown Jr. LM, Zannikos PN, Rainey PM (1998) The effect of fluconazole on the clinical pharmacokinetics of methadone. Clin Pharmacol Ther 63 : 655-662.

37. Kang BC, Yang QY, Cho HK, Suh OK, Shin WG (2002) Influence of fluconazole on the pharmacokinetics of omeprazole in healthy volunteers. Biopharm Drug Dispos 23 $77-81$

38. Gerhart JG, Watt KM, Edginton A, Wade KC, Salerno SN, et al. (2019) Physiologicallybased pharmacokinetic modeling of fluconazole using plasma and cerebrospinal fluid samples from preterm and term infants. CPT Pharmacometrics Syst Pharmacol 8: 500510

39. Bafeltowska JJ, Buszman E (2005) Pharmacokinetics of fluconazole in the cerebrospinal fluid of children with hydrocephalus. Chemotherapy 51: 370-376.

40. Huttova M, Hartmanova I, Kralinsky K, Filka J, J Uher J, et al. (1998) Candida fungemia in neonates treated with fluconazole: report of forty cases, including eight with meningitis. Pediatr Infect Dis J 17: 1012-1015. [Crossref]

41. Pérez JA, Johnson RH, Caldwell JW, Arsura EL, Nemecheck P (1995) Fluconazole therapy in coccidioidal meningitis maintained with intrathecal amphotericin B. Arch Intern Med 155: 1665-1668. [Crossref]

42. Kaplan YC, Koren G (2015) Fluconazole use during breastfeeding. Can Fam Physician 61: 875-876.

43. Liu D, Zhang C, Wu L, Zhang L, Zhang L (2020) Fetal outcomes after materna exposure to oral antifungal agents during pregnancy: A systematic review and metaanalysis. Int J Gynaecol Obstet 148: 6-13.

44. Mølgaard-Nielsen D, Svanström H, Melbye M, Hviid A, Pasternak B (2016) Association between use of oral fluconazole during pregnancy and risk of spontaneous abortion and stillbirth. JAMA 315: 58-67. [Crossref]

45. Howley MM, Carter TC, Browne ML, Romitti PA, Cunniff CM, et al. (2016) Fluconazole use and birth defects in the national birth defects prevention study. $\mathrm{Am} \mathrm{J}$ Obstet Gynecol 214: e1-9.

46. Pursley TJ, Blomquist IK, Abraham J, Andersen HF, J A Bartley JA (1996) Fluconazoleinduced congenital anomalies in three infants. Clin Infect Dis 22: 336-340.

47. Bérard A, Sheehy O, Zhao J-P, Gorgui J, Bernatsky S, et al. (2019) Associations between low- and high-dose oral fluconazole and pregnancy outcomes: 3 nested casecontrol studies. CMAJ 191: E179-E187.

48. Wilkerson J, McPherson C, Donze A (2010) Fluconazole to prevent systemic funga infections in infants: reviewing the evidence. Neonatal Netw 29: 323-333. [Crossref]

49. Ku LC, Smith PB (2015) Dosing in neonates: Special considerations in physiology and trial design. Pediatr Res 77: 2-9.

50. Schwarze R, Penk A, Pittrow L (2000) Treatment of candidal infections with fluconazole in neonates and infants. Eur J Med 23: 203-208.

51. Manzoni P, Mostert M, Jacqz-Aigrain E, Farina D (2009) The use of fluconazole in neonatal intensive care units. Arch Dis Child 94: 983-987.

52. Kaufman D (2004) Fungal infection in the very low birthweight infant. Curr Opin Infect Dis 17: 253-259. [Crossref]

53. Viscoli C, Castagnola E, F Fioredda F, Ciiravenga B, Barignione G, et al. (1991) Fluconazole in the treatment of candidiasis in immunocompromised children. Antimicrob Agents Chemother 35: 365-367.

54. Driessen M, Ellis JB,Muwazi F, De Villiers FP (1997) The treatment of systemic candidiasis in neonates with oral fluconazole. Ann Trop Paediatr 17: 263-271.

55. Frattarelli DAC, Reed MD, Giacoia GP, Aranda JV (2004) Antifungals in systemic neonatal candidiasis. Drugs 64: 949-968. [Crossref]

56. Marchisio P, Principi N (1994) Treatment of oropharyngeal candidiasis in HIV-infected children with oral fluconazole. Eur J Clin Microbiol Infect Dis 13: 338-340. 
57. Godamudunage MP, Lampe JN, and Emily E. Scott EE (2017) Comparison of cytochrome P450 3A4 and 3A7 with azole inhibitors. Pharmacology 31: 1-10.

58. Niwa T, Shiraga T, Takagi A (2015) Effect of antifungal drugs on cytochrome p450 (cyp) 2c9, cyp2c19, and cyp3a4 activities in human liver microsomes. Biol Pharm Bull 28: $1805-1808$.

59. Leroux S, Jacqz-Aigrain E, Elie V, Legrand F, Barin-Le Guellec C, et al. (2018) Pharmacokinetics and safety of fluconazole and micafungin in neonates with systemic candidiasis: A randomized, open-label clinical trial. Br J Clin Pharmacol 84: 19891999.

60. Piper L, Brian SP, Hornik, CP, Cheifetz I, Barrett JS, et al. (2011) Fluconazole loading dose pharmacokinetics and safety in infants. Ped Infect Dis J 30: 375-378.

61. Murakoso K, Minagawa R, Echizen H (2018) Developmental changes of fluconazole clearance in neonates and infants in relation to ontogeny of glomerular filtration rate: literature review and data analysis. J Pharm Health Care Sci 4.

62. Momper JD, Capparelli EV, Wade KC, Kantak A, Dhanireddy R, et al. (2016) Population pharmacokinetics of fluconazole in premature infants with birth-weights less than 750 grams. Antimicrob Agents Chemother 60: 5539-5545. [Crossref]

63. Wade KC, Wu D, Kaufman DA, Ward RM, Benjamin Jr DK, et al. (2008) Population pharmacokinetics of fluconazole in young infants. Antimicrob Agents Chemother 52: 4043-4049.

64. Watt KM, Gonzalez D, Benjamin Jr. DK, Kim L. R. Brouwer KLR, Kelly, Wade KC, et al. (2015) fluconazole population pharmacokinetics and dosing for prevention and treatment of invasive candidiasis in children supported with extracorporeal membrane oxygenation. Antimicrob Agents Chemother 59: 3935-3943.

65. Lee JW, Seibel NL, Amantea M, Whitcomb P, Pizzo PA, et al. (1992) Safety and pharmacokinetics of fluconazole in children with neoplastic diseases. J Pediatr 120: 987-993. [Crossref]
66. Asner SA, Giulieri S, Manuel Diezi M, Marchetti O, et al. (2015) Acquired multidrug antifungal resistance in candida lusitaniae during therapy. Antimicrob Agents Chemother 59: 7715-7722.

67. Kovacicova G, Krupova Y, Lovaszova M, A. Roidova A, Trupl J, et al. (2000) Antifungal susceptibility of 262 bloodstream yeast isolates from a mixed cancer and non-cancer patient population: is there a correlation between in-vitro resistance to fluconazole and the outcome of fungemia? $J$ Infect Chemother 6: 216-221.

68. Marchaim D, Lemanek L, Bheemreddy S, Kaye KS, Sobel JD (2012) Fluconazoleresistant candida albicans vulvovaginitis. Obstet Gynecol 120: 1407-1414. [Crossref]

69. Krcmery V, Barnes AJ (2002) Non-albicans candida spp. causing fungaemia: pathogenicity and antifungal resistance. J Hosp Infect 50: 243-260.

70. Tyczkowska-Sieron E, Gaszynski W, Tyczkowski J, Glowacka A (2014) Analysis of the relationship between fluconazole consumption and non-c. albicans candida infections. Med Mycol 52: 758-765.

71. Fan X, Xiao M, Liao K, Kudinha T, Wang H, et al. (2017) Notable increasing trend in azole non-susceptible candida tropicalis causing invasive candidiasis in china (august 2009 to july 2014): molecular epidemiology and clinical azole consumption. Front Microbiol 8: 464. [Crossref]

72. Goemaere B, Lagrou K, Spriet I, Hendrickx M, Becker P (2018) Clonal spread of candida glabrata bloodstream isolates and fluconazole-resistance affected by prolonged exposure: a 12-year single-center study in belgium. Antimicrob Agents Chemother 62: e00591-18.

73. Steinbach WJ, Perfect JR, Schell WA, Thomas J. Walsh TJ, et al. (2004) In vitro analyses, animal models, and 60 clinical cases of invasive aspergillus terreus infection. Antimicrob Agents Chemother 48: 3217-3225.

74. Cowen LE, Sanglard D, Howard SJ, Rogers PD, Perlin DS (2014) Mechanisms of antifungal drug resistance. Cold Spring Harb Perspect Med 5: a019752. [Crossref]

Copyright: (2020 Pacifici GM. This is an open-access article distributed under the terms of the Creative Commons Attribution License, which permits unrestricted use, distribution, and reproduction in any medium, provided the original author and source are credited. 